\title{
ESTUDO COMPARADO DA GLÂNDULA METAPLEURAL E SUA SECREÇÃO EM DIFERENTES CASTAS DE TRÊS ESPÉCIES DE Atta (HYMENOPTERA : FORMICIDAE)
}

\section{LUCIANA GUERRA DE GUSMÃo}

Engenheiro Agrônomo

Orientador: Prof. Dr. OCTAVIO NAKANO

Tese apresentada à Escola Superior de Agricultura "Luiz de Queiroz", Universidade de São Paulo, para obtenção do título de Doutor em Ciências, Área de concentração: Entomologia

PIRACICABA

Estado de São Paulo - Brasil

Julho de 2000 


\section{Dados Internacionais de Catalogaçāo na Publicaçāo (CIP) DIVISÃO DE BIBLIOTECA E DOCUMENTAÇÃO - Campus "Luiz de Oueiroz"/USP}

Gusmão, Luciana Guerra de

Estudo comparado da glândula metapleural e sua secreção em diferentes castas de três espécies de Alta (Hymenoptera : Formicidae) / Luciana Guerra de Gusmão. - - Piracicaba, 2000.

$60 \mathrm{p}$.

Tese (doutorado) - Escola Superior de Agricultura Luiz de Queiroz, 2000. Bibliografia.

1. Composição quimica 2. Formiga-cortadeira 3. Glândula de secreção exócrina 4. Microscopia eletrônica de varredura 5. Microscopia eletrônica de transmissão I. Título

CDD 632.796 
Ao mestre e amigo Flávio,

por ter me estendido a mão no momento mais difícil,

DEDICO

À todos os mirmecologistas, 


\section{AGRADECIMENTOS}

Ao Prof. Dr. Octavio Nakano, pela orientação e oportunidades oferecidas;

Ao Conselho Nacional de Tecnologia e Pesquisa (CNPq) e à Coordenação de Aperfeiçoamento de Pessoal de Nivel Superior (CAPES), pela concessão das bolsas de estudos durante a realização do curso;

Ao Prof. Dr. Flávio Henrique Caetano, do Departamento de Biologia da UNESP - Rio Claro, pela orientação, incentivo e amizade;

À Monika Iamonte e Antônio Teruyoshi Yabuky, do Laboratório de Microscopia Eletrônica da UNESP - Rio Claro, pelo coleguismo, presteza, ensinamentos práticos e serviços técnicos prestados;

Aos amigos e mentores Alci Enimar Loeck e Ronaldo Alfredo Schröter, pelo apoio nos momentos dificeis e sabedoria transmitida, que influenciaram nas tomadas de decisões mais sensatas;

Aos colegas agrônomos Enrico de Beni Arrigoni, Sérgio Zambon e Oscar Ramon Bendeck pela credibilidade profissional e amizade durante minha permanência em Piracicaba; 
À amiga Odinete Murari pela convivência, sugestões, coleguismo, confiança e principalmente amizade durante todo o curso e ao amigo José Maurício Bento pelas dicas e sugestões;

Aos professores Klaus Jaffé, da Universidade Simón Bolivar (Caracas-Venezuela), e Oscar Bahia Filho, da BF Consulting, pela orientação, críticas e correções durante a condução deste trabalho;

Às bibliotecárias Eliana Maria Garcia Sabino e Kátia Maria de Andrade Ferraz pela atenção e auxílio nas pesquisas e citações bibliográfica;

A todos aqueles que, direta ou indiretamente, colaboraram para a execução deste trabalho. 


\section{SUMÁRIO}

Página

RESUMO viii

SUMMARY $\mathrm{x}$

1 INTRODUÇÃO 1

2 REVISÃO DE LITERATURA 3

3 ULTRAMORFOLOGIA COMPARADA DA GLÂNDULA METAPLEURAL EM DIFERENTES CASTAS DE TRÊS ESPÉCIES DE Atta (HYMENOPTERA: FORMICIDAE) ....

RESUMO

SUMMARY

3.1 INTRODUÇÃO

3.2 MATERIAL E MÉTODOS

3.3 RESULTADOS E DISCUSSÃO

3.4 CONCLUSÕES

4 ULTRA-ESTRUTURA COMPARADA DA GLÂNDULA METAPLEURAL DE RAINHAS DE Atta bisphaerica FOREL, 1908 E Atta sexdens rubropilosa FOREL, 1908 (HYMENOPTERA: FORMICIDAE)

RESUMO

SUMMARY

4.1 INTRODUÇÃO

4.2 MATERIAL E MÉTODOS

4.3 RESULTADOS E DISCUSSÃO 26

4.4 CONCLUSÕES 
5 COMPOSIÇÃO QUÍMICA DA SECREÇÃO DA GLÂNDULA METAPLEURAL DE DIFERENTES CASTAS DE Atta bisphaerica FOREL, 1908 E Atta capiguara GONÇALVES. 1944 (HYMENOPTERA:

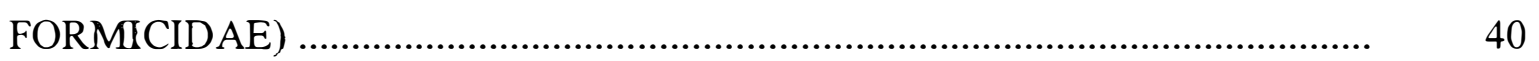

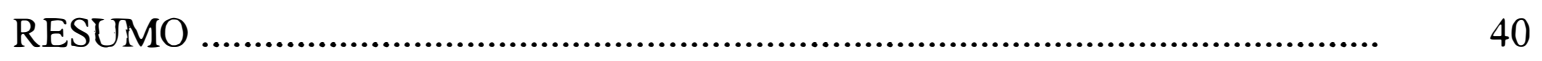

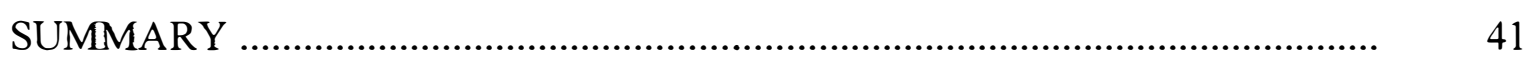

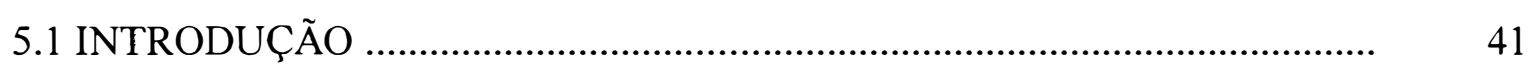

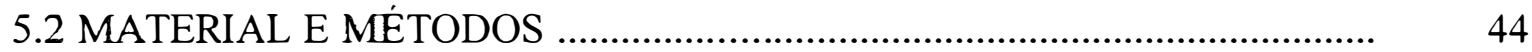

5.3 RESULTADOS E DISCUSS ÃO ............................................................... 46

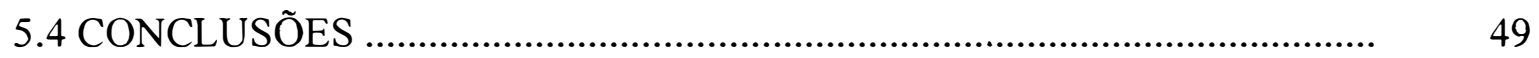

6 CONCLUSÕES GERAIS .......................................................................... 50

REFERÊNCIAS BIBLIOGRÁFICAS ….................................................... 51 


\title{
ESTUDO COMPARADO DA GLÂNDULA METAPLEURAL E SUA SECREÇÃO EM DIFERENTES CASTAS DE TRÊS ESPÉCIES DE Atta (HYMENOPTERA : FORMICIDAE)
}

\author{
Autor: LUCIANA GUERRA DE GUSMÃO \\ Orientador: Prof. OCTAVIO NAKANO
}

\section{RESUMO}

Supõe-se que o insucesso das inúmeras tentativas de criação em laboratório de Atta bisphaerica e A. capiguara está relacionado com a menor capacidade de assepsia de suas colônias em relação as demais espécies do gênero Atta. Neste sentido, um dos caminhos importantes a ser seguido é o estudo da glândula metapleural.

A microscopia eletrônica de varredura (MEV) foi utilizada para o estudo morfológico da glândula metapleural de diferentes castas femininas de Atta bisphaerica, A. capiguara e $A$. sexdens rubropilosa. Não houve diferenças ultramorfológicas interespecíficas da glândula metapleural das espécies estudadas. Porém, foi observada diferença intraespecífica no tamanho da glândula que aumentou à medida que aumentou o tamanho do indivíduo. Os resultados não mostraram qualquer evidência, em $A$. bisphaerica e $A$. capiguara, que possa ser correlacionada com o insucesso da criação desta espécies em laboratório.

A ultra-estrutura da glândula metapleural de rainhas (fecundadas) de Atta bisphaerica e $A$. sexdens rubropilosa foi analisada por meio de microscopia eletrônica de transmissão (MET). Os resultados mostraram a presença de complexo de Golgi típico (cisternas achatadas), retículo endoplasmático rugoso na forma lamelar (lamella annullata), abundante retículo endoplasmático liso, mitocôndrias de formas variadas (arredondadas, longas, em anel e derivadas), vacúolos heterofágicos e peroxissomos. No 
citoplasma encontrou-se a célula coletora fazendo interdigitações com a célula secretora. $\mathrm{O}$ espaço entre as células é fechado por junções septadas. Não foram observadas diferenças ultra-estruturais entre as glândulas das espécies estudadas. O material examinado não mostrou qualquer evidência da presença de glicogênio no seu citoplasma.

Utilizando a técnica de cromatografia em fase gasosa e espectrometria de massas (GC-MS) a composição química da secreção metapleural de jardineiras, forrageadoras e rainha de Atta bisphaerica e forrageadoras de $A$. capiguara foi analisada. Na primeira espécie, além de um éster, foram encontrados ácido fenil acético, $\beta$-hidroxiácidos e hidrocarbonetos insaturados, que foram associados à atividade microbiana da secreção. Diferenças qualitativas foram observadas entre as duas espécies e comparadas com a secreção de outras Atta spp. . A ausência do ácido indolacético em ambas espécies foi relacionada com desenvolvimento do fungo simbionte. 


\title{
COMPARED STUDY OF METAPLEURAL GLAND AND ITS SECRETION IN DIFFERENTS CASTES OF THREE SPECIES OF Atta (HYMENOPTERA : FORMICIDAE)
}

\author{
Author: LUCIANA GUERRA DE GUSMÃO \\ Adviser: Prof. OCTAVIO NAKANO
}

\section{SUMMARY}

The unsuccess of Atta bisphaerica and A. capiguara rearing in laboratory can be caused by the low efficience of its metapleural gland against fungi and bacteria in comparing with other Atta spp.

Morphological differences among the metapleural glands of castes of Atta bisphaerica, $A$. capiguara and $A$. sexdens rubropilosa were examined under scanning electron microscope (SEM). No differences were observed in gland morphology among the same castes of these species but there were differences of size of the metapleural gland among castes in the same species. No evidences were found that morphological characteristics of metapleural gland in $A$. bisphaerica and $A$. capiguara are related with the unsuccess of those species rearing in laboratory.

The ultrastructural characteristics of metapleural gland of Atta bisphaerica and A. sexdens rubropilosa mated queens were observed by transmission electron microscopy (TEM). The cytoplasm of the secretory cells was characterized by the presence of typical Golgi apparatus (sacs and flat vesicles), rough endoplasmic reticulum (parallel lamelae), a lot of smooth endoplasmic reticulum, many types of mitochondria (rounded, elongated, ring-shaped and derivated), vesicles, peroxisomes and collecting cell interlocking with secretory cell. The space between these cells is close by septate junctions. There were no differences between glands of these species. Glycogen deposit were not found in the cytoplasm. 
The chemical analyses of the secretions of the metapleural glands of minor workers, workers and queen of Atta bisphaerica and workers of A. capiguara were carried out by using a gas cromatography-mass spectrometry (GC-MS) technique. In $A$. bisphaerica, beside an ester, were found phenylacetic acid, $\beta$-hidroxyacids and unsaturated hidrocarbons which were related with antimicrobial activity of metapleural secretion. There were qualitative differences in the acidic composition of secretion between both species which were compared with other Atta spp. . The absence of indoleacetic acid in $A$. bisphaerica and A. capiguara was related with the growth of symbion fungus. 


\section{INTRODUÇÃO}

O problema "formigas cortadeiras", que inclui várias espécies da tribo Attini, onde o gênero Atta é o mais representativo, está situado como um dos mais importantes da agricultura nacional. Apesar dos conhecimentos já adquiridos e do aperfeiçoamento dos meios de combate, elas continuam sendo consideradas o inimigo número um das lavouras, por atacarem praticamente todas as plantas cultivadas e até mesmo a pastagem nativa. Estão disseminadas por todo o território nacional e efetuam sua ação predadora durante todo o ano. A primeira preocupação do agricultor é a formiga, pois exige dele gastos consideráveis com formicidas e mão-de-obra, tanto antes da instalação da cultura, ocupando-lhe grande parte das lides agrícolas, como durante todas as fases do cultivo (Juruena \& Cachapuz, 1980).

Atualmente, há uma crescente preocupação com a natureza e a defesa do meio ambiente, desenvolvendo-se métodos de controle de pragas integrados com uma menor utilização de produtos químicos. Segundo Vilela (1995), nenhuma substância com ação formicida será comercializada se não for, necessariamente, de baixo impacto ambiental, o que certamente limitará sua capacidade de extingüir formigueiros nos moldes antigos. Por isso, é imprescindível a utilização do conhecimento científico acumulado sobre a morfologia, biologia, o comportamento e a ecologia das formigas cortadeiras para que haja um racional e efetivo controle das mesmas, com ênfase aos processos mais ecológicos.

As espécies Atta bisphaerica Forel, 1908 e Atta capiguara Gonçalves, 1944, conhecidas respectivamente como "saúva mata-pasto" e "saúva parda" são consideradas importantes pragas no Estado de São Paulo, principalmente em regiões onde houve substituição da vegetação natural por monocultivos constituídos de gramíneas 
(Amante,1972; Forti,1985 ; Forti \& Ichinose, 1993 ). A ocorrência $A$. bisphaerica, pode ser observada também nos Estados de MG, MT e RJ enquanto que $A$. capiguara pode ser encontrada em MG, MT, PR e GO (Della Lucia, 1993). O Centro de Tecnologia Copersucar admite perdas médias de 3 toneladas de cana-de-açúcar/sauveiro/ano em usinas do Estado de São Paulo ( Precetti et al., 1988).

Colônias de Atta sexdens piriventris Santschi, 1919, A. sexdens rubropilosa Forel,1908 e A. laevigata (F. Smith, 1858) são mantidas sem maiores problemas em condições de laboratório em Universidades do RS, SP e MG (Loeck,1982; Bento,1991; Hebling et al.,1993; Silveira Neto et al.,1993; Brancher,1993; Anjos \& Santana,1994; Loeck et al., 1994) mas a metodologia empregada para estas espécies não se enquadra para A. bisphaerica e A. capiguara.

No caso dessas espécies, estudos bioecológicos são dificultados devido à ausência de uma metodologia adequada para o desenvolvimento e estabelecimento de colônias em laboratório. As informações a respeito dessas formigas são bastante escassas, já que os poucos trabalhos foram conduzidos no campo e por um número muito restrito de pesquisadores.

Supõe-se que o insucesso das inúmeras tentativas de criação em laboratório de Atta bisphaerica e A capiguara está relacionado com a menor capacidade de assepsia de suas colônias em relação as demais espécies do gênero Atta. Neste sentido, um dos caminhos importantes a ser seguido é o estudo da glândula metapleural.

Desta forma, este trabalho teve por objetivo, verificar a existência de diferenças morfológica, ultramorfológica e ultra-estrutural, intra e interespecíficas da glândula metapleural de diferentes castas de A. bisphaerica, A. capiguara e A. sexdens rubropilosa, bem como analisar quali-quantitativamente a composição química da secreção da glândula metapleural de $A$. bisphaerica e $A$. capiguara. 


\section{REVISÃO DE LITERATURA}

A glândula metapleural é também chamada de metasternal ou metatorácica e é uma particularidade em Formicidae. Em vários gêneros essa glândula é ausente ou significativamente reduzida, além disso, em machos sua inexistência é bastante comum.

Embora esteja presente na maioria das espécies, essa estrutura tem uma grande variação com relação ao tamanho e à forma. Presente em cada lado do metatórax, a glândula metapleural consiste de um grupo de células, onde cada uma é drenada por um duto até um saco coletor membranoso que conduz diretamente para uma cavidade esclerotizada (câmara armazenadora). Externamente, essa estrutura é freqüentemente marcada por uma bula pronunciada e uma abertura em forma de fenda (Brown, 1968; Tulloch et al., 1962; Hölldobler \& Engel-Siegel, 1984; Billen \& Van Boven, 1987; Fanfani \& Dazzini, 1991).

A ultra-estrutura da glândula metapleural tem sido, até o momento, pouco estudada. Foram relatados trabalhos envolvendo Myrmecia nigrocincta (Tulloch et al., 1962), Diacamma rugosum, D. vagans (Schoeters \& Billen, 1992), Atta bisphaerica, A. laevigata, A. sexdens sexdens e A. sexdens rubropilosa (Schoeters \& Billen, 1993).

Segundo Noirot \& Quennedey (1974), três classes de células glandulares podem ser definidas no que diz respeito à cutícula e o caminho de saída da secreção. A glândula metapleural é formada por células glandulares do tipo 3. Para as glândulas compostas de células da classe 3 , a presença de compartimentos extracelulares pode ser considerada uma boa adaptação para a produção de produtos mais ou menos tóxicos. As organelas celulares podem elaborar e secretar precursores não tóxicos, os quais eventualmente conduzirão a produtos finais, por meio de sucessivas reações em um ou vários níveis.

As secreções das glândulas exócrinas têm reconhecida importância no comportamento e fisiologia dos insetos. Entre várias hipóteses sugeridas para a função da glândula metapleural, Tulloch et al. (1962) e Brown (1968) propuseram que essa produziria um feromônio de reconhecimento entre os membros da mesma colônia que seria liberado sobre o tegumento e espalhado para o resto do corpo com as tíbias e tarsos. Maschwitz et al. (1970) efetuaram alguns ensaios com operárias e rainhas de 
Myrmica laevinodis, M. rubida, Formica rufa e $F$. polyctena e constataram não haver efeito, interespecífico ou intraespecífico, da secreção sobre o reconhecimento de indivíduos.

Existem algumas espécies de formigas em que a secreção da glândula metapleural atua como uma poderosa substância anti-séptica que protege a superficie do corpo do inseto e seu ninho contra microrganismos, como acontece em Atta sexdens, Myrmica laevinodis e M. rubida ( Maschwitz et al., 1970; Maschwitz, 1974). Em Crematogaster difformis a secreção serve como anti-séptico, mas quando liberada em grandes quantidades também pode repelir outros animais (Attygalle et al., 1989). Já em C. inflata, a secreção atua como substância de alarme/defesa ( Maschwitz et al., 1970; Maschwitz, 1974).

Schildknecht \& Koob (1971) isolaram compostos de Atta sexdens, Myrmica laevinodis, Messor barbarus e Acromyrmex subterraneus que inibiram o crescimento de algumas bactérias patogênicas e alguns fungos de solo. A secreção metapleural de Myrmecia nigriscapa teve um efeito supressor sobre o desenvolvimento micelial de alguns fungos de solo e fungos entomopatogênicos (Beattie et al.,1985, 1986). Em M. urens (Peakall et al., 1990) e em Iridomyrmex sp. (Ramsey, 1995) essa mesma substância afetou a germinação e qualidade de grãos de pólen.

Segundo Veal et al. (1992), a secreção da glândula metapleural de M. gulosa apresentou propriedades antimicrobianas, afetando bactérias gram-positivas, gramnegativas e leveduras do gênero Candida.

De acordo com Brown (1968), a ausência, não funcionalidade ou tamanho reduzido da glândula metapleural, seriam justificados pela necessidade de acasalamento entre machos e rainhas virgens da mesma espécie, mas de colônias diferentes (Dorylinae e Myrmicinae), penetração de rainhas parasitas que invadem outros ninhos para que as operárias destes criem sua prole (grupo que inclui pelo menos 35 espécies) e formigas escravagistas (Polyergus spp.).

Em 27 espécies de Camponotus e seis de Polyrhachis investigadas por Hölldobler \& Engel-Siegel (1984), apenas C. gigas possuia glândula metapleural. A ausência dessa glândula em formigas parasitas ( Oecophylla, Polyrhachis, 
Dendromyrmex e a maioria das Camponotus) deve-se ao fato de que essas fariam uso das secreções das formigas hospedeiras, além disso, essas formigas arborícolas estariam muito menos expostas a microrganismos do que espécies terrestres, e portanto, uma glândula metapleural com função de assepsia seria desnecessária.

Várias espécies nas quais operárias e rainhas apresentaram essa glândula bastante desenvolvida, os machos não possuiam esse órgão, provavelmente porque esses indivíduos vivem um período de tempo relativamente curto dentro do ninho e são muito menos numerosos do que as operárias, não havendo necessidade deles produzirem secreções anti-sépticas (Hölldobler \& Engel-Siegel, 1984).

A hipótese de que a secreção metapleural, ausente em larvas e machos, é transferida das operárias para esses indivíduos contribuindo para a inibição da microbiota cuticular, foi confirmada por Mackintosh et al. (1999) ao estudar Myrmecia gulosa.

As glândulas exócrinas tiveram muitas de suas funções primitivas modificadas ao longo do processo evolutivo e a maioria delas passou a produzir feromônios (Baiocco \& Cunha, 1992). No caso de Solenopsis geminata, a secreção da glândula metapleural atua como feromônio territorial (Jaffe \& Puche, 1984). O mesmo foi observado em Pheidole pallidula onde apenas as operárias mínimas apresentaram forte atividade de marcação territorial (Cammaerts \& Cammaerts, 1998).

Monomorium pharaonis provavelmente sintetiza feromônio de alarme, pois rainhas virgens apresentaram células secretoras maiores e com dutos coletores mais carregados de secreção em relação às rainhas fecundadas, podendo refletir uma maior atividade fisiológica dessas estruturas em uma determinada fase da vida das rainhas (Baiocco \& Cunha, 1992). 


\section{ULTRAMORFOLOGIA COMPARADA DA GLÂNDULA METAPLEURAL DE DIFERENTES CASTAS DE TRÊS ESPÉCIES DE Atta (HYMENOPTERA: FORMICIDAE)}

\section{RESUMO}

A microscopia eletrônica de varredura (MEV) foi utilizada para o estudo morfológico da glândula metapleural de diferentes castas femininas de Atta bisphaerica, A. capiguara e $A$. sexdens rubropilosa. Não houve diferenças ultramorfológicas interespecíficas da glândula metapleural das espécies estudadas. Porém, foi observada diferença intraespecífica no tamanho da glândula que aumentou à medida que aumentou o tamanho do indivíduo. Em rainhas ela foi expressivamente maior que nas demais castas. Os resultados não mostraram qualquer evidência, em $A$. bisphaerica e $A$. capiguara, que possa ser correlacionada com o insucesso da criação desta espécies em laboratório.

Palavras-chave: Atta, formiga cortadeira, glândula exócrina, morfologia 


\section{ULTRAMORPHOLOGY OF THE METAPLEURAL GLAND IN DIFFERENT CASTES OF THREE SPECIES OF Atta (HYMENOPTERA:FORMICIDAE)}

\section{SUMMARY}

Morphological differences among the metapleural glands of castes of Atta bisphaerica, $A$. capiguara and $A$. sexdens rubropilosa were examined under scanning electron microscope (SEM). No differences were observed in gland morphology among the same castes of these species but there were differences of size of the metapleural gland among castes in the same species. No evidences were found that morphological characteristics of metapleural gland in $A$. bisphaerica and $A$. capiguara are related with the unsuccess of those species rearing in laboratory.

Key words: $A t t a$, exocrine gland, leaf cutter ant, morphology

\subsection{INTRODUÇÃO}

A glândula metapleural está presente na grande maioria das formigas, podendo produzir uma substância própria com diferente função para cada espécie. Embora essa glândula seja considerada uma característica exclusiva de Formicidae, são poucos os estudos de morfologia existentes .

A estrutura geral dessa glândula é uniforme entre muitas subfamílias, sendo formada basicamente por um conjunto de células secretoras, cada uma contendo dutos individualizados e por um grande reservatório. $\mathrm{O}$ número de células secretoras, bem como o tamanho e a forma do reservatório são variáveis (Brown, 1968; Tulloch et al., 
1962; Hölldobler \& Engel-Siegel, 1984; Billen \& Van Boven, 1987; Fanfani \& Dazzini, 1991; Schoeters \& Billen, 1992, 1993).

A presença de uma câmara coletora cuticular em Atta spp. leva a um dos mais elevados graus de desenvolvimento em formigas. Em alguns Ponerinae e Formicinae, a presença de uma câmara coletora parece ser menos importante (Schoeters \& Billen, 1993). Segundo Baiocco \& Cunha (1992), as células secretoras abrem-se no interior da câmara coletora, liberando suas secreções através de um disco poroso na cutícula, que em Diacamma vagans aparece como uma única e grande placa na parte anterior da parede do átrio contendo em torno de 500 orificios (Schoeters \& Billen, 1992) e em Myrmecia nigrocincta caracteriza-se por vários discos perfurados que variam muito no tamanho (5 a $20 \mu)$ e no número de dutos que acomodam (1 a \pm 13$)$ (Tulloch et al., 1962).

Ao contrário do que acontece com a maioria das outras glândulas em Atta, a glândula metapleural não apresenta nenhum suprimento muscular próximo ao orificio de saída da secreção, sugerindo que a liberação da secreção é facilitada pela existência de uma aresta cuticular entre a abertura glandular e as pernas posteriores. Essa característica, segundo Schoeters \& Billen (1993), não é observada em espécies mais primitivas pertencentes a Myrmicinae e Ponerinae.

A secreção da glândula metapleural atua como uma poderosa substância antiséptica que protege a superficie corporal de diferentes espécies de formigas cortadeiras e seus respectivos ninhos contra microrganismos (Maschwitz at al., 1970; Schildknecht \& Koob, 1971; Iizuka et al., 1979; Nascimento et al., 1996).

Acredita-se que uma das prováveis causas do insucesso das inúmeras tentativas de criação de $A$. bisphaerica e $A$. capiguara, em laboratório, reside no fato de que a glândula metapleural dessa espécie não atue de forma tão eficiente na assepsia da colônia, como nas demais espécies do gênero Atta. Nesse sentido, este trabalho teve como objetivo verificar a existência de diferenças morfológica e ultramorfológica, intra e interespecifica da glândula metapleural de diferentes castas de A. bisphaerica, $A$. capiguara e A. sexdens rubropilosa. 


\subsection{MATERIAL E MÉTODOS}

O trabalho foi realizado no Laboratório de Microscopia Eletrônica do Departamento de Biologia, do Instituto de Biociências da Universidade Estadual Paulista-UNESP-Campus de Rio Claro, SP.

\subsubsection{Coleta de material}

Com exceção das rainhas fecundadas $(25 \mathrm{~mm})$ e das jardineiras $(3 \mathrm{~mm})$ que foram coletadas em sauveiros jovens (3-4 meses, com panela única) localizados no campo, as forrageadoras (10 $\mathrm{mm})$ e os soldados $(15 \mathrm{~mm})$ de Atta sexdens rubropilosa foram coletados no sauveiro artificial do Departamento de Entomologia da ESALQ/USP, Piracicaba-SP.

Todos os exemplares de A. bisphaerica, A. capiguara foram coletados no campo, de ninhos jovens e/ou adultos e suas medidas seguiram o padrão da espécie anterior. As coletas foram efetuadas em localidades onde ocorreu a revoada a partir do mês de outubro, do ano anterior, próximas ao município de Piracicaba, SP, para facilitar o transporte e evitar o "stress" do material coletado.

Todas as formigas, assim obtidas, foram levadas vivas para o laboratório. No caso dos ninhos jovens, esses foram coletados integralmente (fungo + formigas) com o auxílio de enxada e colher, e acondicionados em potes plásticos de $300 \mathrm{ml}$, com tampa perfurada, permitindo assim melhor preservação do material vivo, principalmente no que diz respeito às rainhas. Do material obtido de sauveiros adultos, acondicionaram-se apenas as formigas ( $\pm 50 /$ recipiente) em potes plásticos de $300 \mathrm{ml}$, com os bordos internos recobertos com vaselina líquida (faixa de $\pm 1 \mathrm{~cm}$ ). Tal precaução foi tomada para evitar a fuga dos indivíduos. 


\subsubsection{Ultramorfologia}

A microscopia eletrônica de varredura (MEV) foi utilizada para o estudo morfológico da glândula metapleural das várias castas femininas de Atta sexdens rubropilosa A. bisphaerica e de A. capiguara. A remoção da glândula foi feita por meio de dissecação das formigas vivas mergulhadas em fixador Karnovsky (tampão fosfato de sódio $0,08 \mathrm{M}, \mathrm{pH} 7,3$; paraformaldeído $4 \%$ e glutaraldeído 2,1\%) com o auxílio de tesoura de dissecação para insetos, pinças de ponta fina e estereomicroscópio (Zeiss). Os insetos foram previamente anestesiados com choque térmico a uma temperatura de aproximadamente $-20{ }^{\circ} \mathrm{C}$ e posteriormente imobilizados com alfinetes entomológicos, em placa de Petri com mistura de cera de abelha com parafina corada.

Após a dissecação, as glândulas foram transferidas para recipientes contendo o mesmo fixador, onde permaneceram por um período mínimo de 2 horas. Posteriormente todo o material foi desidratado em série crescente de soluções de álcool $(70,80,90,95$, $100 \%$ ), por 15 minutos cada, sendo que no álcool $100 \%$ foram 3 banhos. Em seguida, as glândulas foram transferidas para uma mistura de álcool e acetona (1:1) e finalmente acetona $100 \%$ P.A., também com duração de 15 minutos cada banho.

Terminada essa etapa, o material foi levado ao ponto crítico (Balzers CPD/030), para completar a desidratação, e adequadamente fixado em suportes cilíndricos de alumínio, com o auxílio de fita dupla face. Por meio de vaporizador (Balzers SCD 050), as glândulas foram revestidas com ouro-paladium e levadas ao microscópio eletrônico de varredura (Jeol JMS P15) e com voltagem de aceleração de $15 \mathrm{Kv}$, onde foram analisadas e fotografadas ( filme Neopan-SS-120).

\subsection{RESULTADOS E DISCUSSÃO}

Em todas as castas de Atta bisphaerica, A. capiguara e A. sexdens rubropilosa a abertura da glândula metapleural apresentou a forma de uma fenda semi-circular localizada próxima às coxas posteriores. No caso de jardineira, forrageadora e soldado, não houve diferença entre as espécies (Figura 1), mas as rainhas de $A$. sexdens 
rubropilosa apresentaram o orificio de saida com aproximadamente o dobro do tamanho do orificio de $A$. bisphaerica (Figura 2). Essa diferença não foi observada em rainhas de Myrmecia gulosa e M. urens (Angus et al., 1993).

Assim como foi relatado por Schoeters \& Billen (1993), a região circunvizinha ao orificio de saída mostrou-se lisa, sem nenhum tipo de esculturação, como o modelo hexagonal típico da reticulação conspícua encontrada no resto do corpo de Atta spp. (Figura 1) .

Verificou-se que a área ao redor da abertura da glândula forma uma espécie de sulco cuja função, provavelmente, é permitir o escoamento da secreção em direção às coxas posteriores (Figura 1), de modo que o movimento destas últimas facilite o espalhamento da secreção metapleural pelo resto do corpo, protegendo, por exemplo, regiões intersegmentais que são mais susceptíveis à penetração de microrganismos entomopatogênicos.

Não foram encontrados pêlos associados ao orificio de saída da glândula metapleural, como no caso de Camponotus gigas, Catalacus intrudens, Crematogaster sp., Podomyrma pulchra (Hölldobler \& Engel-Siegel, 1984), Crematogaster striatula (Fanfani \&Dazzini, 1991), Diacamma rugosum e D. vagans (Schoeters \& Billen, 1992).

Diferente do que foi descrito para D. rugosum e D. vagans (Schoeters \& Billen, 1992), que apresentaram no centro da glândula metapleural células secretoras arredondadas e, na periferia, células alongadas ou cilindricas; as células glandulares em Atta spp. apresentaram-se, de maneira geral, arredondadas, independente de sua localização (Figuras 3C e D, 4D, 5).

Enquanto Schoeters \& Billen (1993) encontraram para A. laevigata, A. bisphaerica, $A$. sexdens sexdens e $A$. sexdens rubropilosa, células secretoras usualmente agnupadas em cachos de aproximadamente 20 células, neste trabalho, não houve uniformidade intra ou interespecífica no número de células por cacho nem quanto ao número de cachos por glândula nas diferentes castas de $A$. bisphaerica, A. capiguara e A. sexdens rubropilosa (Figuras 3 e 4 ).

De acordo com o relatado por Schoeters \& Billen (1993), as jardineiras apresentaram um número menor de células secretoras quando comparadas com as 
demais castas, entretanto, quando se comparou o tamanho da glândula metapleural com o tamanho do tórax, foi nas jardineiras que ela se mostrou mais desenvolvida (Figura 3A). Esta observação é pertinente quando analisada sob o ponto de vista funcional da glândula metapleural, pois se for considerada uma colônia recém fundada, onde inicialmente existe apenas a rainha e uma pequena massa micelial do fungo simbionte, $\mathrm{e}$ que as primeiras operárias que emergem na colônia são as mínimas (Hölldobler \& Wilson, 1990), serão estes indivíduos os principais responsáveis pelo estabelecimento e desenvolvimento de novos ninhos, através da liberação contínua da secreção da glândula metapleural cuja função é inibir o crescimento de microorganismos do solo e estimular o desenvolvimento do fungo simbionte.

Bot \& Boomsma (1996) tiveram duas interpretações para o tamanho relativamente grande da glândula metapleural em operárias minor de formigas cortadeiras. Uma é que o excesso de antibiótico produzido pelas jardineiras é usado para proteção do fungo simbionte diretamente contra outros microrganismos e a outra é que as jardineiras necessitam de mais proteção que as outras castas, pois sua principal tarefa é a limpeza do jardim de fungo, e portanto, seu contato com microrganismos é maior

Caetano (1984) relatou que as jardineiras de $A$. bisphaerica, A. capiguara, $A$. laevigata e A. sexdens rubropilosa apresentaram, proporcionalmente ao tamanho do tubo digestivo, o maior papo dentre as castas estudadas. Segundo o autor, as diferenças encontradas de casta para casta, admitindo-se que todas têm a mesma alimentação, devem ser atribuidas às suas funções.

A glândula metapleural da rainha mostrou-se bastante desenvolvida (Figura 3D), o que não surpreendeu, devido ao seu tamanho $( \pm 25 \mathrm{~mm}$ ) e a função que desempenha na colônia inicialmente fundada. Nessa casta, o número de células secretoras foi superior às 400 unidades relatadas por Schoeters \& Billen (1993) (Figuras 3D e 4D). O tamanho da glândula metapleural aumentou à medida que aumentou o tamanho do indivíduo, sendo que em rainhas ela foi expressivamente maior que nas demais castas ( Figura 3).

Os resultados obtidos por Angus et al. (1993) juntamente com dados, previamente publicados, de operárias de 13 outras espécies de formigas (Tulloch et al., 1962; Höldobler \& Engel-Siegel, 1984), permitiram aos autores, por meio de uma 


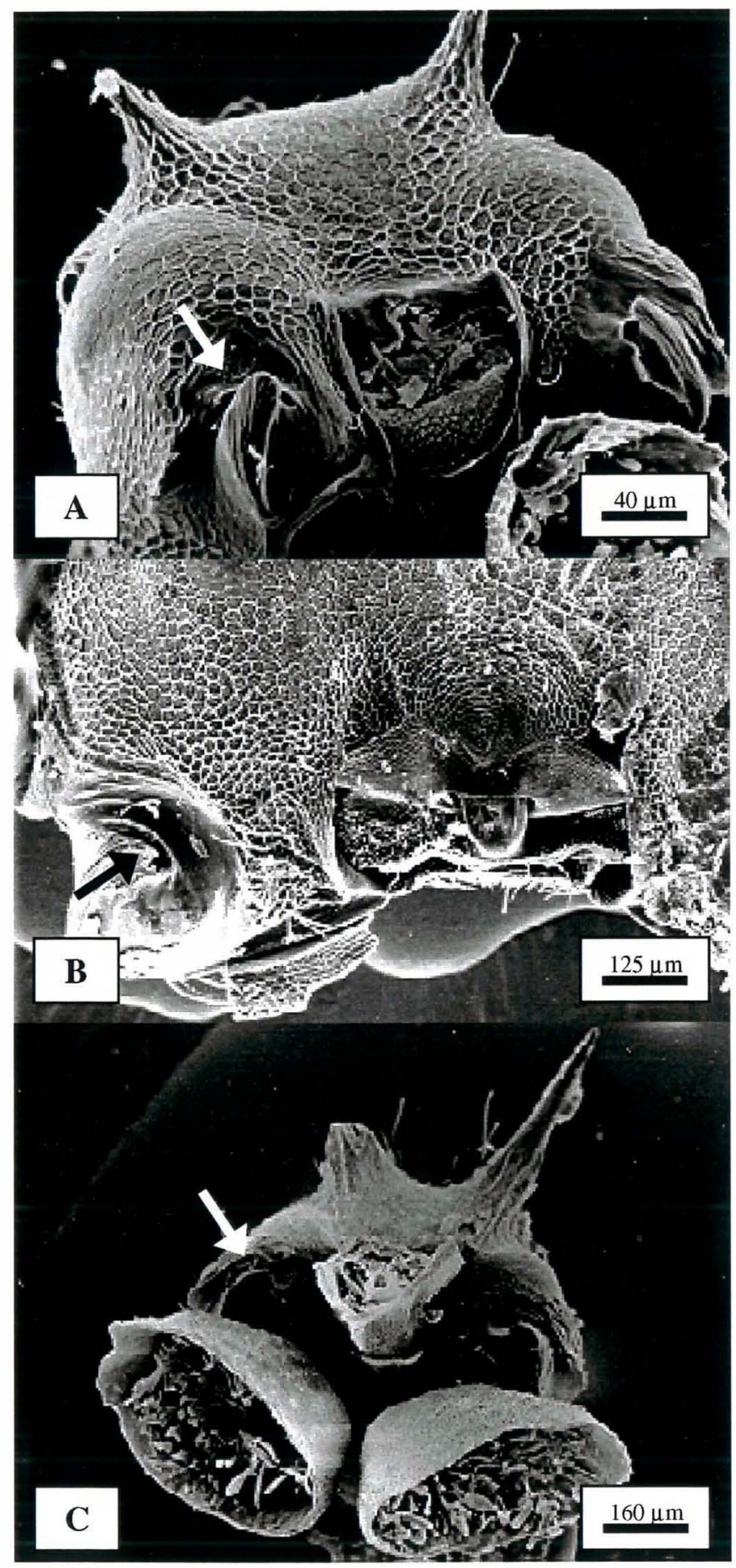

Figura 1. Abertura da glândula metapleural (seta). A- jardineira (Atta sexdens rubropilosa), B- soldado (A. capiguara) e C- forrageadora ( Atta sexdens rubropilosa). 

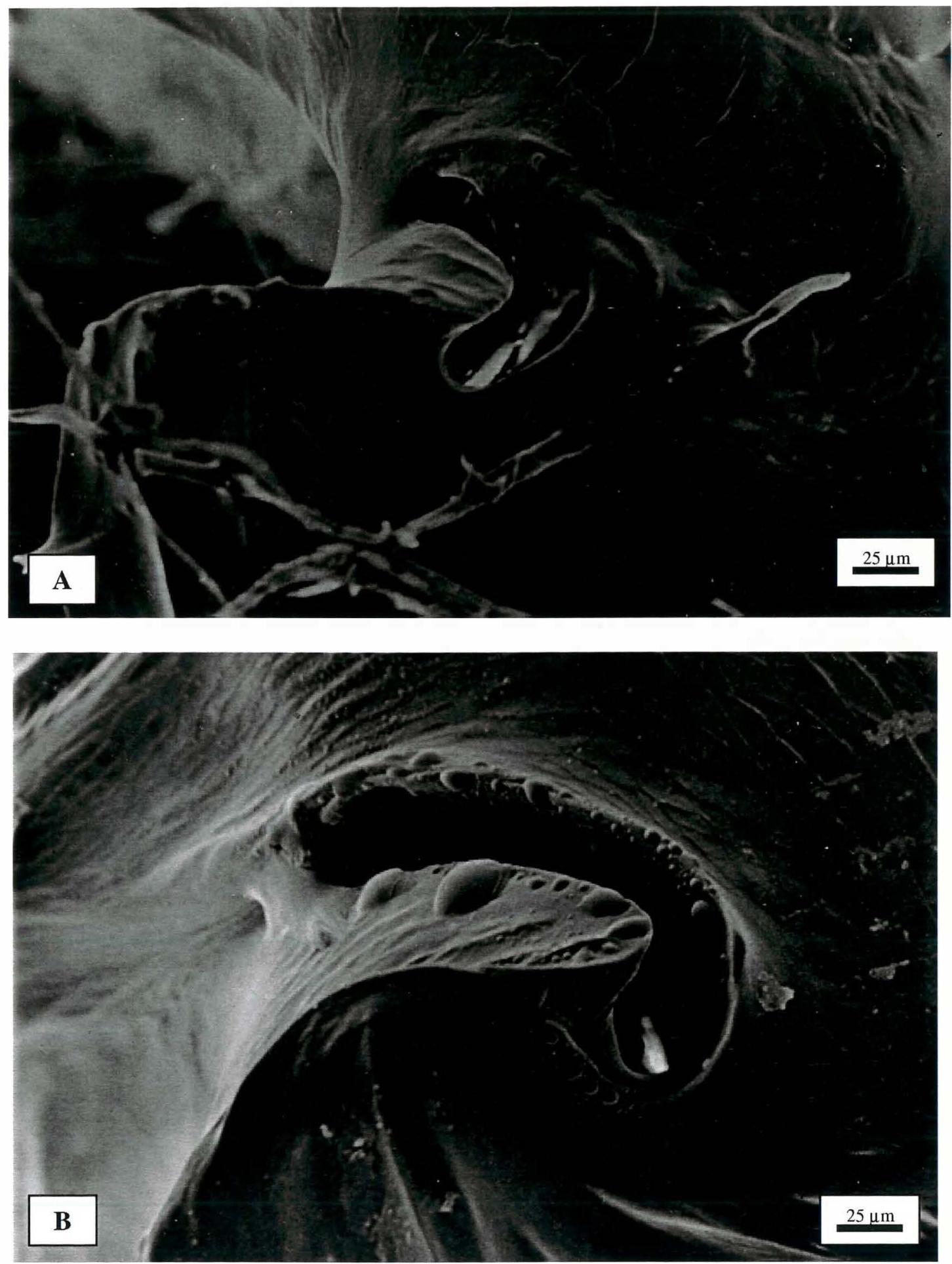

Figura 2. Abertura da glândula metapleural de rainha. A-Atta bisphaerica e B-Atta sexdens rubropilosa. 

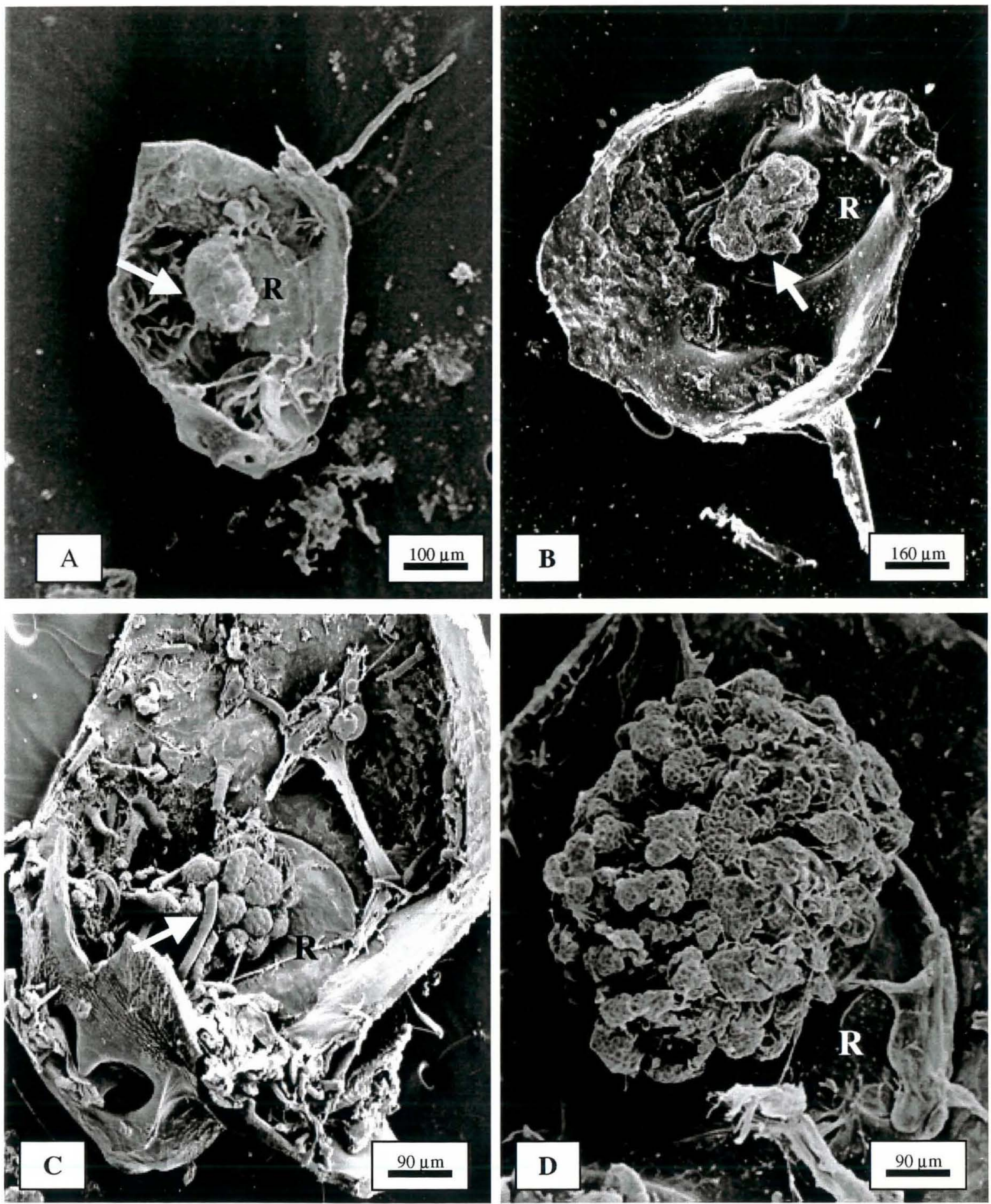

Figura 3. Glândula metapleural de Atta sexdens rubropilosa. A- jardineira, B-forrageadora, C-soldado e D- rainha. R- reservatório. 


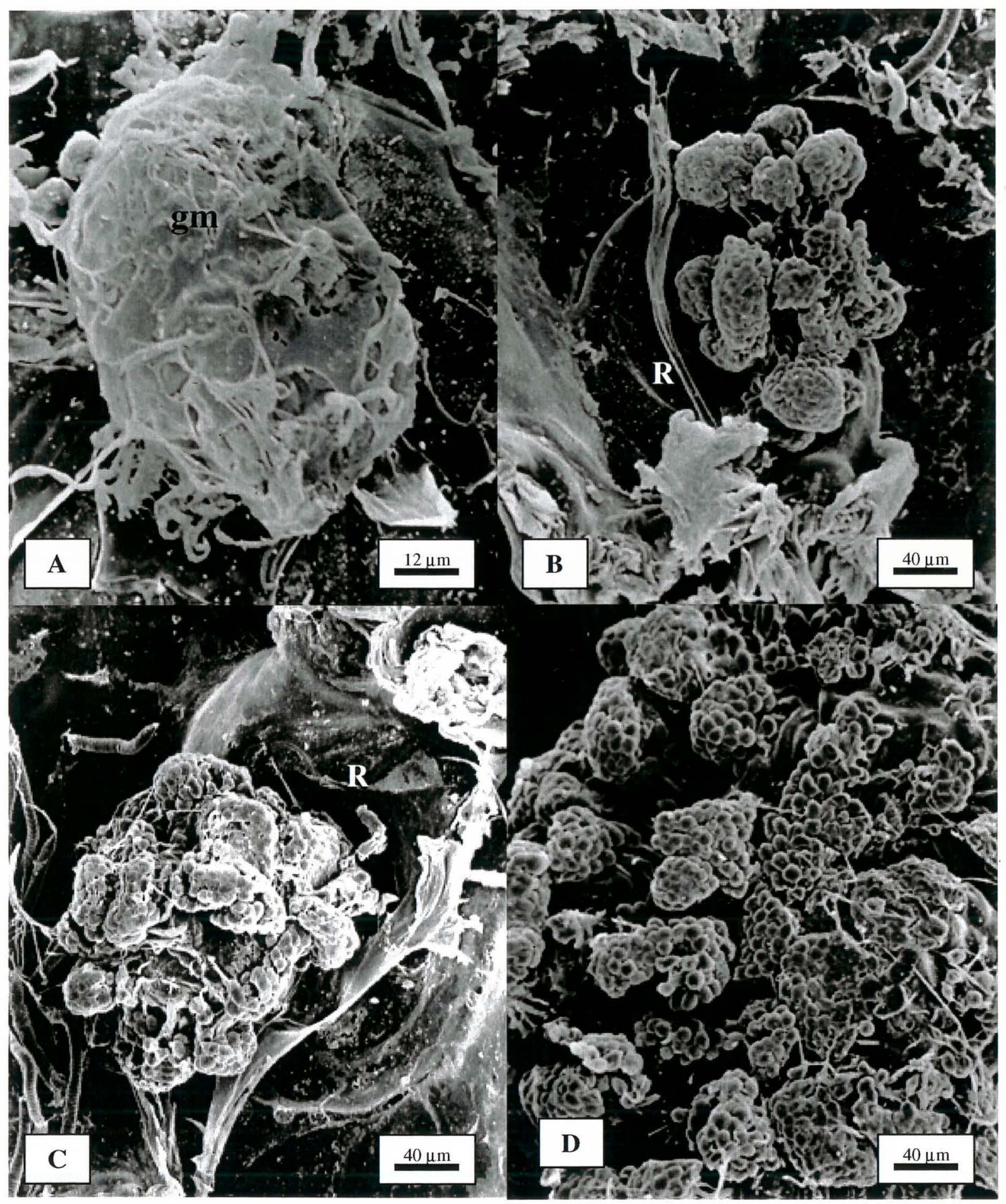

Figura 4. Glândula metapleural de Atta sexdens rubropilosa. A- jardineira, B-forrageadora, C- soldado e D- rainha. R- reservatório e gm- glândula metapleural recoberta por tecido conjuntivo. 


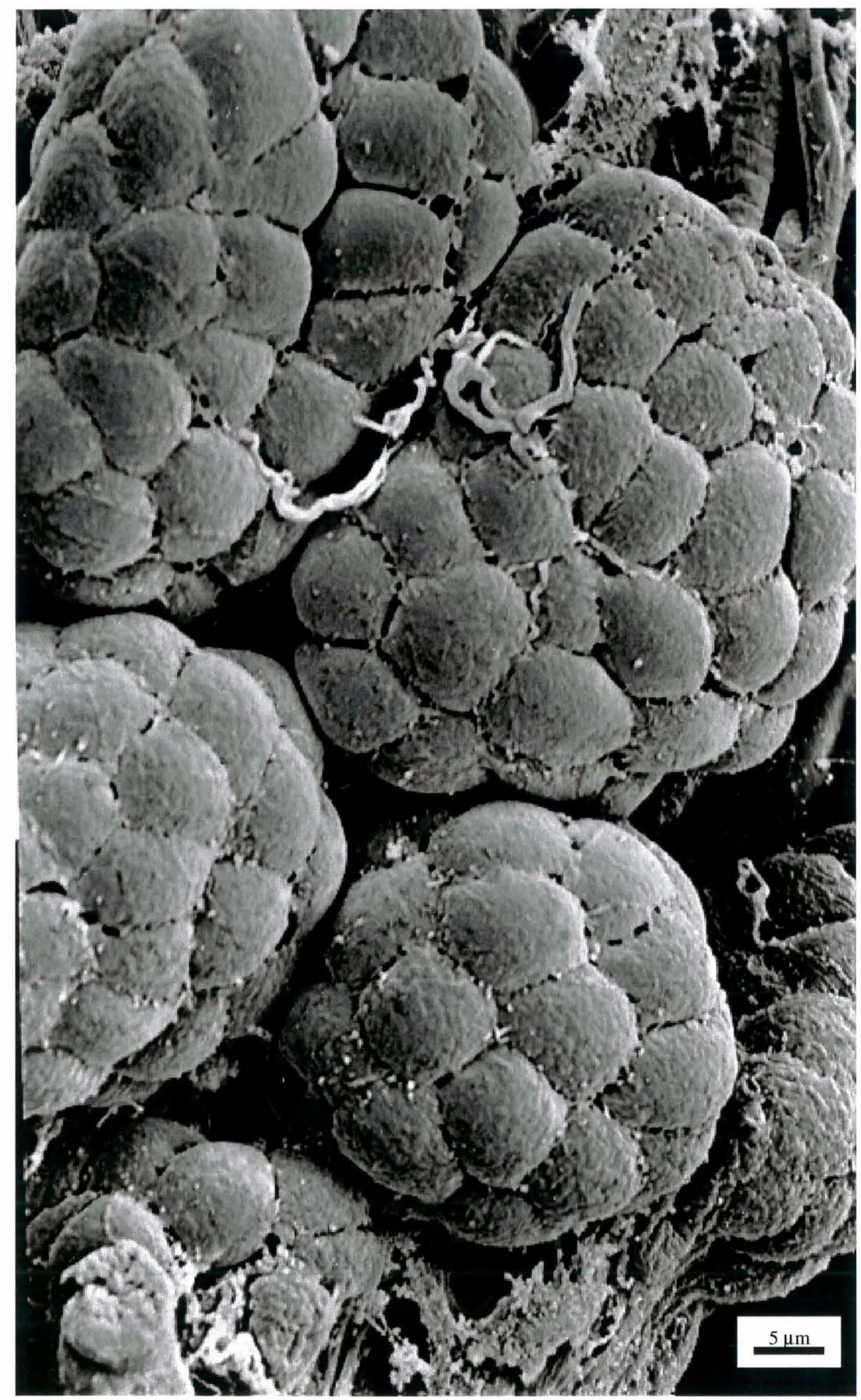

Figura 5. Cachos de células secretoras da glândula metapleural de Atta sexdens rubropilosa (soldado). 


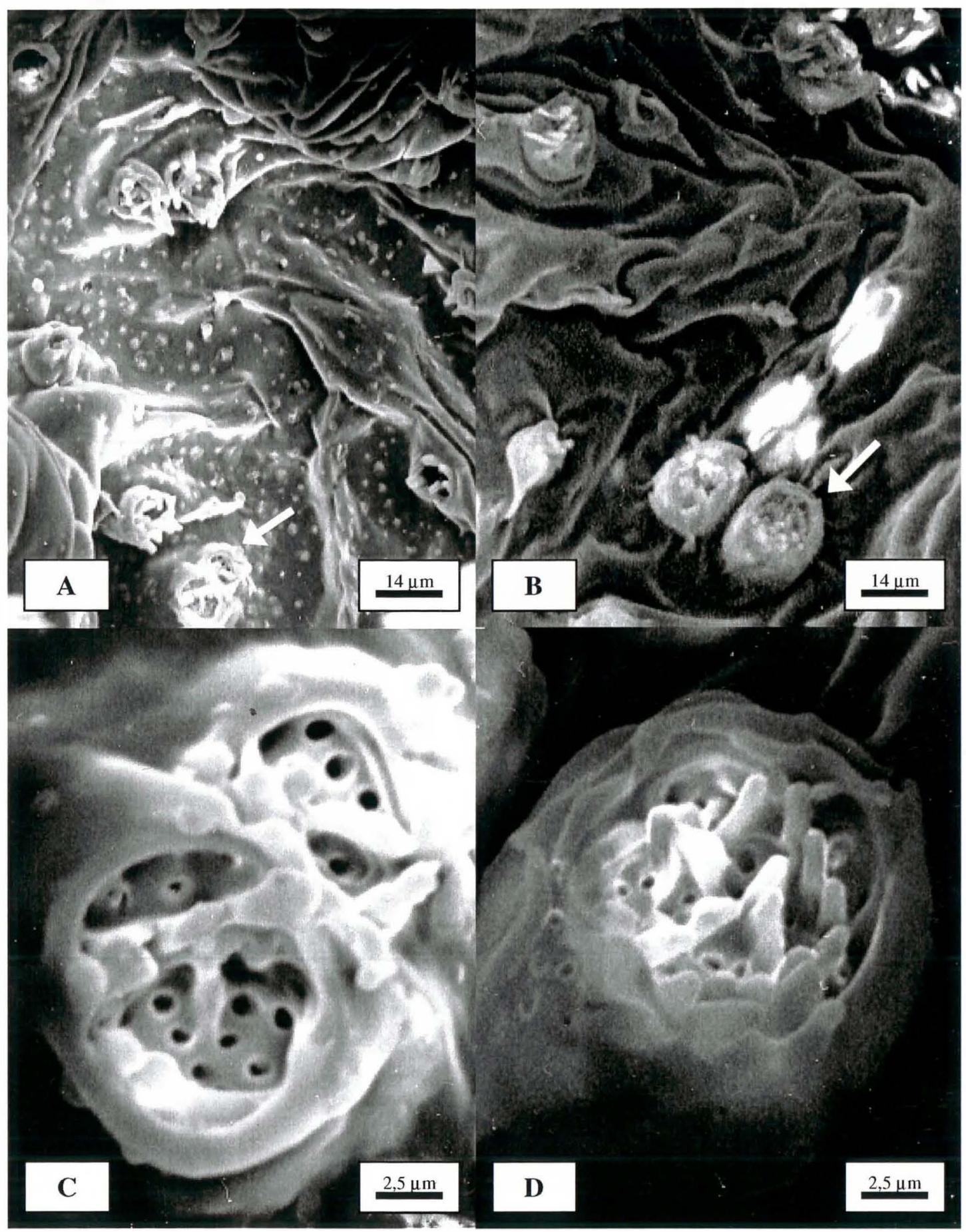

Figura 6. Superfície interna da câmara coletora. A e C-Atta bisphcierica, B e D- Atta sexdens rubropilosa. 
análise de regressão, obter uma correlação positiva e significativa entre o número de células da glândula metapleural e o tamanho do corpo, sugerindo que a variação no tamanho da glândula é funcionalmente relacionado à área de superficie. Estes autores, contudo, não apresentaram o número de células de cada glândula.

Além disso, Angus et al. (1993) verificaram que a rainha, tanto de M. gulosa quanto M. urens, apresentou aproximadamente duas vezes mais células do que as operárias, atribuindo uma função de assepsia preventiva do local de postura. O mesmo foi observado por Hölldobler \& Engel-Siegel (1984) em outros gêneros, reforçando a hipótese de Wilson (1980) citada por Bot \& Boomsma (1996) de que os órgãos das formigas são mais desenvolvidos nas castas onde são mais cruciais.

Em todas as castas observadas, a câmara coletora sempre esteve recoberta pelas células glandulares e o reservatório esteve sempre visível (Figuras 3, 4B e 4C). No caso das rainhas, observou-se que a superficie interna da câmara coletora é bastante irregular e apresentou estruturas circulares perfuradas semelhantes às descritas por Tulloch et al. (1962) (Figura 6). O mesmo deve ocorrer nas demais castas já que morfologicamente suas glândulas metapleurais são semelhantes.

As estruturas de Atta cephalotes, A. sexdens (Hölldobler \& Engel-Siegel, 1984), operárias minor de $A$. sexdens sexdens, soldados de $A$. bisphaerica, rainhas de $A$. laevigata, operárias e operárias minor de A. sexdens rubropilosa (Schoeters \& Billen, 1993), quando comparadas com as observadas neste trabalho, demonstraram que, nas espécies de Atta até agora estudadas, não há diferenças morfológicas interespecíficas mas existe diferença entre o tamanho da glândula metapleural nas diferentes castas.

\subsection{CONCLUSÕES}

Não há diferenças ultramorfológicas interespecífica da glândula metapleural de jardineiras, forrageadoras, soldados e rainhas de Atta bisphaerica, A. capiguara e A. sexdens rubropilosa.

O tamanho da glândula metapleural aumenta à medida que aumenta o tamanho do indivíduo, sendo que em rainhas ela é expressivamente maior que nas demais castas. 
As características ultramorfológicas da glândula metapleural de $A$. bisphaerica e A. capiguara não mostram qualquer evidência que possa ser correlacionada com o insucesso da criação destas espécies em laboratório. 


\section{ULTRA-ESTRUTURA COMPARADA DA GLÂNDULA METAPLEURAL DE RAINHAS DE Atta bisphaerica FOREL, 1908 E Atta sexdens rubropilosa FOREL, 1908 (HYMENOPTERA: FORMICIDAE)}

\section{RESUMO}

A ultra-estrutura da glândula metapleural de rainhas (fecundadas) de Atta bisphaerica e $A$. sexdens rubropilosa foi analisada por meio de microscopia eletrônica de transmissão (MET). Os resultados mostraram a presença de complexo de Golgi típico (cisternas achatadas), retículo endoplasmático rugoso na forma lamelar (lomella annullata), abundante retículo endoplasmático liso, mitocôndrias de formas variadas (arredondadas, longas, em anel e derivadas), vacúolos heterofágicos e peroxissomos. No citoplasma encontrou-se a célula coletora fazendo interdigitações com a célula secretora. O espaço entre as células é fechado por junções septadas. Não foram observadas diferenças ultra-estruturais entre as glândulas das espécies estudadas. $\mathrm{O}$ material examinado não mostrou qualquer evidência da presença de glicogênio no seu citoplasma.

Palavras-chave: Atta, formiga cortadeira, glândula exócrina, ultra-estrutura 


\section{ULTRASTRUCTURE OF METAPLEURAL GLAND OF QUEENS OF Atta bisphaerica FOREL, 1908 AND Atta sexdens rubropilosa FOREL, 1908 (HYMENOPTERA: FORMICIDAE)}

\section{SUMMARY}

The ultrastructural characteristics of metapleural gland of Atta bisphaerica and $A$. sexdens rubropilosa mated queens were observed by transmission electron microscopy (TEM). The cytoplasm of the secretory cells was characterized by the presence of typical Golgi apparatus (sacs and flat vesicles), rough endoplasmic reticulum (parallel lamelae), a lot of smooth endoplasmic reticulum, many types of mitochondria (rounded, elongated, ring-shaped and derivated), vesicles, peroxisomes and collecting cell interlocking with secretory cell. The space between these cells is close by septate junctions. There were no differences between glands of these species. Glycogen deposit were not found in the cytoplasm.

Key words: Atta, exocrine gland, leaf cutter ant, ultrastructure

\subsection{INTRODUÇÃO}

A glândula metapleural está presente na grande maioria das formigas, podendo produzir uma substância própria com diferente função para cada espécie. Embora essa

glândula seja considerada uma característica exclusiva de Formicidae, sua ultra-estrutura tem sido, até o momento, pouco estudada.

A estrutura geral da glândula metapleural é uniforme entre muitas subfamílias, sendo formada basicamente por um conjunto de células secretoras, cada uma contendo dutos individualizados e por um grande reservatório (Brown, 1968; Tulloch et al., 1962; 
Hölldobler \& Engel-Siegel, 1984; Billen \& Van Boven, 1987; Fanfani \& Dazzini, 1991; Schoeters \& Billen, 1992, 1993).

Tulloch et al. (1962) ao estudarem a ultra-estrutura da glândula metapleural de Myrmecia nigrocincta, deram ênfase ao canalículo, considerado uma conecção independente entre as células secretoras e o saco reservatório. Segundo os autores, essa estrutura intracelular é bem adaptada para a coleta e o transporte da secreção metapleural. O canalículo percorre o interior da célula de maneira tortuosa, permitindo através dos cortes ultra-finos, uma visão tanto transversal quanto longitudinal do mesmo ( Tulloch et al., 1962; Schoeters \& Billen, 1992, 1993 ). Esse duto coletor faz contatos sinuosos, como microvilosidades, com a célula secretora e podem sofrer deformações de acordo com o volume de secreção ( Schoeters \& Billen , 1992).

Em M. nigrocincta, um grande número de mitocôndrias distribuídas em altas concentrações ao lado de numerosas gotículas de secreção ao redor do canalículo foram observadas por Tulloch et al. (1962). Segundo Schoeters \& Billen (1992), que estudaram a glândula metapleural de Diacamma rugosum e D. vagans, a aparência e abundância de mitocôndrias variam durante o processo secretor. Essas organelas podem apresentar-se longas, delgadas e mais eletrondensas ou arredondadas e mais eletronlúcidas.

Tulloch et al. (1962) não encontraram complexo de Golgi nas células da glândula metapleural de operárias de $M$. nigrocincta . Entretanto, em D. rugosum e D. vagans a presença dessa organela foi bastante comum (Schoeters \& Billen, 1992). Embora encontrado, o complexo de Golgi não foi uma constante nas células da glândula metapleural de operárias minor de $A$. sexdens sexdens, soldados de $A$. bisphaerica, rainhas de $A$. laevigata, operárias e operárias minor de $A$. sexdens rubropilosa (Schoeters \& Billen, 1993).

O citoplasma das células secretoras de D. rugosum e $D$. vagans foi caracterizado pela presença de retículo endoplasmático liso bem desenvolvido (Schoeters \& Billen, 1992). Em operárias de $A$. sexdens rubropilosa, Schoeters \& Billen (1993) encontraram retículo endoplasmático rugoso bastante desenvolvido com típica organização paralela. Os autores atribuiram a presença dos diferentes retículos à produção substâncias com volatilidade diferente. 
A secreção da glândula metapleural atua como uma poderosa substância antiséptica que protege a superfície corporal de diferentes espécies de formigas cortadeiras e seus respectivos ninhos contra microrganismos (Maschwitz at al., 1970; Schildknecht \& Koob, 1971; Iizuka et al., 1979; Nascimento et al., 1996).

Supõe-se que o insucesso das inúmeras tentativas de criação em laboratório de Atta bisphaerica e A. capiguara esteja relacionado com a menor capacidade de assepsia de suas colônias em relação as demais espécies do gênero Atta. Neste sentido, um dos caminhos importantes a ser seguido é o estudo da glândula metapleural.

Desta forma, este trabalho teve como objetivo, verificar a existência de diferenças ultra-estruturais da glândula metapleural de rainhas (fecundadas) de $A$. bisphaerica e $A$. sexdens rubropilosa.

\subsection{MATERIAL E MÉTODOS}

O trabalho foi realizado no Laboratório de Microscopia Eletrônica do Departamento de Biologia, do Instituto de Biociências da Universidade Estadual Paulista-UNESP-Campus de Rio Claro, SP.

\subsubsection{Coleta de material}

Rainhas fecundadas ( $25 \mathrm{~mm}$ ) foram coletadas em sauveiros jovens (3-4 meses, com panela única) de Atta sexdens rubropilosa e A. bisphaerica, respectivamente, nos municípios de Charqueada, SP e Conchas, SP. Com exceção de Atta sexdens rubropilosa, o material foi identificado pela técnica de eletroforese horizontal em gel de poliacrilamida para diferenciação de espécies por meio de padrões isoenzimáticos (Augustin et al., 1998).

As coletas foram efetuadas em localidades onde a revoada ocorreu a partir do mês de outubro do ano anterior, próximas ao município de Piracicaba, para facilitar o transporte e evitar o "stress" das formigas. Os ninhos foram coletados integralmente (fungo + formigas) com o auxilio de enxada e colher, e acondicionados em potes 
plásticos de $300 \mathrm{ml}$, com tampa perfurada, permitindo assim melhor preservação das rainhas.

\subsubsection{Uitra-estrutura}

A microscopia eletrônica de transmissão (MET) foi utilizada para o estudo ultraestrutural do epitélio secretor da glândula metapleural de Atta sexdens rubropilosa e Atta bisphaerica. A remoção da glândula foi feita por meio de dissecação de formigas vivas mergulhadas em fixador Kamovsky (tampão fosfato de sódio 0,08M, pH 7,3; paraformaldeído $4 \%$ e glutaraldeído $2,1 \%$ ) com o auxílio de tesoura de dissecação para insetos, pinças de ponta fina e estereomicroscópio (Zeiss). Os insetos foram previamente anestesiados com choque térmico a uma temperatura de aproximadamente $-20{ }^{\circ} \mathrm{C}$ e posteriormente imobilizados com alfinetes entomológicos, em placa de Petri com mistura de cera de abelha com parafina corada.

Após a dissecação, as glândulas foram transferidas para recipientes contendo o mesmo fixador, permanecendo por um período mínimo de 2 horas.

Após a fixação o material foi lavado em tampão fosfato $0,1 \mathrm{M}$, três vezes, por 15 minutos cada banho. A seguir o material foi pós-fixado em tetróxido de ósmio $\left(\mathrm{OsO}_{4}\right)$ a $1 \%$ com tampão fosfato $0,1 \mathrm{M}$ por duas horas no escuro, após o que se seguiu lavagem em tampão fosfato $0,1 \mathrm{M}$ por duas vezes, por 15 minutos cada. O material assim preparado foi levado para solução de acetato de uranila a $2 \%$ ( preparada com álcool $10 \%$ ), mantido por duas horas à temperatura ambiente, sendo posteriormente encaminhado para desidratação em série de acetona com concentrações de 50, 70, 90, 95 e $100 \%$ (duas vezes nesta última), por cinco minutos cada banho.

Terminado esse procedimento, todo o material foi embebido em resina EponAraldite mais acetona (1:1), onde permaneceu por 24 horas. Passado esse período, o material foi colocado em resina pura por, no mínimo, 12 horas e incluído em resina Epon-Araldite pura, em moldes de borracha específicos, no qual foi orientado para futuras seç̧ões, e levado para estufa $\left( \pm 60{ }^{\circ} \mathrm{C}\right)$ por, no mínimo, 24 horas, para polimerização. 
Os blocos contendo as glândulas foram cortados com o auxilio de um ultramicrótomo (Porter Blum), utilizando-se navalha de vidro, tanto para os cortes grossos $(0,6 \mu \mathrm{m})$, quanto para os cortes ultra-finos $(0,15$ a $0,2 \mu \mathrm{m})$. Os cortes grossos foram corados com Azur II (1\%) e Azul de Metileno (1\%) e os cortes ultra-finos foram tranferidos para grades de cobre e contrastados com acetato de uranila e citrato de chumbo, utilizando-se um contrastador (Reichert Ultrostainer Leika).

Visto que o processo de rotina não denuncia a presença de glicogênio na célula, efetuou-se o teste de Afzellius com parte do material. Nesta técnica, os cortes ultra-finos foram recolhidos em grade de cobre e tratados com solução de ácido tânico ( $1 \%$ em água destilada) por 30 minutos. Posteriormente, o material foi lavado com água destilada e corado com acetato de uranila ( $4 \%$ em água destilada) por 1 hora. As grades foram novamente lavadas com água destilada, secas e examinadas sem qualquer contrastação.

As lâminas com os cortes grossos foram examinadas em microscópio óptico (Zeiss) e as grades de cobre foram examina das e fotografadas ao microscópio eletrônico de transmissão (Philips CM100).

\section{3 RESULTADOS E DISCUSSÃO}

$\mathrm{O}$ epitélio secretor da glândula metapleural de Atta bisphaerica e $A$. sexdens rubropilosa é composto por células secretoras com intima associação com células coletoras (Figuras 1 e 8). Cada célula coletora é constituída de uma porção que se coloca no interior da célula secretora, contudo sem estar dentro desta. Isto quer dizer que nas interdigitações de contato entre as duas células existe espaço intercelular (Figura $2 \mathrm{~A} \mathrm{e}$ B). Esta porção continua como um duto coletor que desemboca no reservatório (Capítulo $3)$.

Embora esse duto não seja uma organela intracelular da célula secretora, como foi considerado por Tulloch et al. (1962), Schoeters \& Billen (1992) e Schoeters \& Billen (1993), foi possível visualizá-lo transversal e longitudinalmente (Figuras 2, 3A e C), pois a célula faz uma invaginação com a célula secretora de maneira a permitir um contato maior e mais íntimo. Isto também é conseguido, e ampliado, pelas 
microvilosidades de ambas as células (Figuras 3B e D, 8B). O caminho percorrido por esta porção é sinuoso (Figura 8A) o que permite, em certas circunstâncias, a visualização de cortes transversais e longitudinais na mesma célula secretora.

$\mathrm{O}$ citoplasma da célula secretora possui um grande número de mitocôndrias ao redor da célula coletora (Figura 1B, 8B, 9A) o que indica a alta demanda energética nessa região. Segundo Tulloch et al. (1962), provavelmente as próprias mitocôndrias estariam envolvidas na síntese de gotículas da secreção e o transporte ativo, mais do que a permeabilidade passiva, seria o mecanismo responsável pela transferência dos produtos da secreção da célula secretora para a célula coletora.

As mitocôndrias apresentam formas arredondadas, alongadas e em forma de anel (Figuras 4, 5A, 10A). Algumas delas possuem cristas tubulares (Figura 5B) cuja presença caracteriza células com produção de esteróides.

Também observou-se estruturas semelhantes às descritas por Caetano (1998) quando estudou a glândula pós-faríngea de Dinoponera australis. $\mathrm{O}$ autor as denominou de mitocôndrias derivadas pois essas estruturas sugeriram mitocôndrias transformadas, muito grande, com alta eletrondensidade e com arranjo delicado de membrana no seu interior (Figuras $5 \mathrm{C}$ e D).

Apresentando-se como aglomerados ao redor do núcleo, o retículo endoplasmático rugoso (RER) é bastante desenvolvido, sempre no arranjo de lamelas paralelas, que lembram as lamellae anmullata, com grande quantidade de ribossomos aderidos à sua membrana (Figura 6A, 9B). Em alguns casos o RER encontra-se dentro de invaginações das membranas nucleares (Figura 6B).

Schoeters \& Billen (1993) também encontraram retículo endoplasmático rugoso bastante desenvolvido em operárias de $A$. sexdens rubropilosa, e Nascimento et al. (1996), por meio de espectrometria infra-vermelho e teste de ninidrina, verificaram que a secreção metapleural de operárias e soldados de $A$. sexdens rubropilosa contém principalmente proteinas. Esses dados juntamente com os resultados deste trabalho comprovam a sintese de proteinas pelas células da glândula metapleural.

$O$ retículo endoplasmático liso (REL) é muito mais abundante que o RER e encontra-se disperso por todo citoplasma (Figuras 7A e B, 10A). Sabe-se que o REL está 
envolvido na biossíntese de lipídios e que sua quantidade na célula é indicativo de sua função. O complexo de Golgi possui forma típica de cisternas achatadas com vesículas nas extremidades (Figura 7D, 9A).

Estudando a glândula salivar do quarto estágio larval de Neoponera villosa, Zara (1998) encontrou retículo endoplasmático liso apenas em células com complexo de Golgi típico e retículo endoplasmático rugoso lamelar, associando sua presença com diferentes estados fisiológicos da célula.

Tal como identificado por Caetano (1998) na glândula pós-faríngea de Dinoponera australis, a presença de grande quantidade de vacúolos heterofágicos (Figura 7C, 10B) deve estar associada à reciclagem de material celular. Tais vacúolos podem ser lisossomos como o verificado por Falco (1992) para a glândula pós-faríngea de Camponotus rufipes, contudo, no presente trabalho não foi realizada a técnica para a detecção desta organela ao microscópio eletrônico de transmissão (MET).

A existência de grânulos com diferentes eletrondensidades (Figura 7C) mostra a produção de diferentes secreções. Segundo Zara (1998), no lúmen da glândula salivar do quarto estágio larval de Neoponera villosa, ocorrem dois tipos de secreção, o primeiro tipo, menos comum, eletrondenso, e o segundo, mais comum, formado por vesículas de secreção eletronlúcidas.

Em geral, as glândulas exócrinas são ricas em organelas e podem apresentar inúmeras inclusões multilamelares (figuras mielínicas) (Figura 10C) as quais correspondem, provavelmente, a material de secreção que será liberado por entre as microvilosidades (Billen, 1991 citado por Caetano, 1998).

Além dessas organelas, foram encontrados peroxissomos (Figura 10D) que, segundo Alberts et al. (1997) citado por Caetano (1998), por meio de suas catalases utilizam o peróxido de hidrogênio para a oxidação de grande variedade de substratos (fenóis, ácido fórmico, formaldeído e álcool) e cujo objetivo principal é a quebra dos ácidos graxos. Desse modo, os peroxissomos podem estar envolvidos na produção dos compostos (identificados no Capítulo 5) que fazem parte da secreção metapleural das espécies de $A t t a$ aqui estudadas e que são produtos de reações oxidativas. 


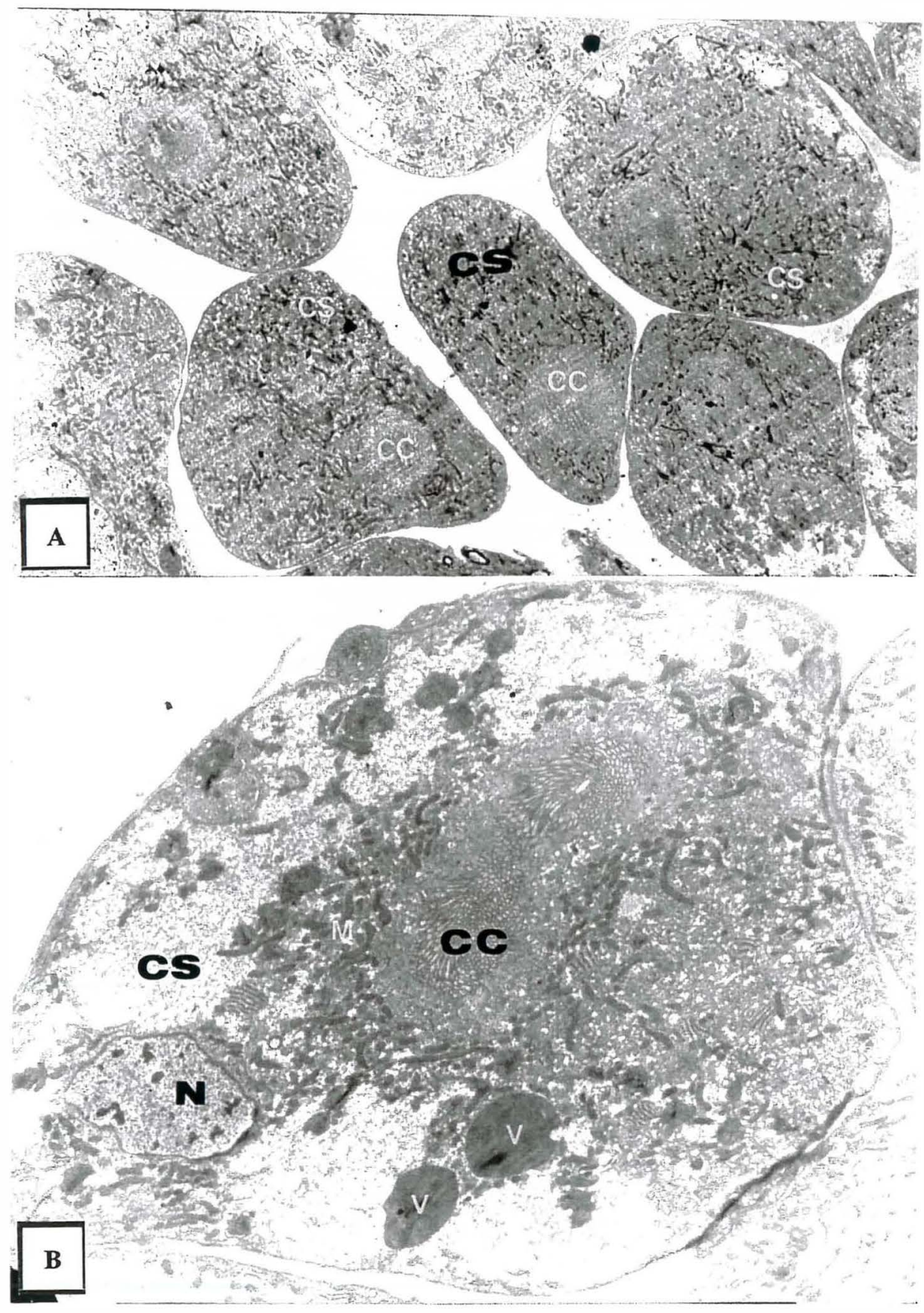

Figura 1. Atta bisphaerica. A- vista geral do epitélio secretor mostrando cortes de células coletoras (CC) no interior de células secretoras (CS). (1850x) B-célula secretora típica (CS) mostrando corte do núcleo $(\mathrm{N})$, mitocôndrias $(\mathrm{M})$, vacúolos heterofágicos (V) e corte oblíquo da célula coletora (CC). (3480x) 


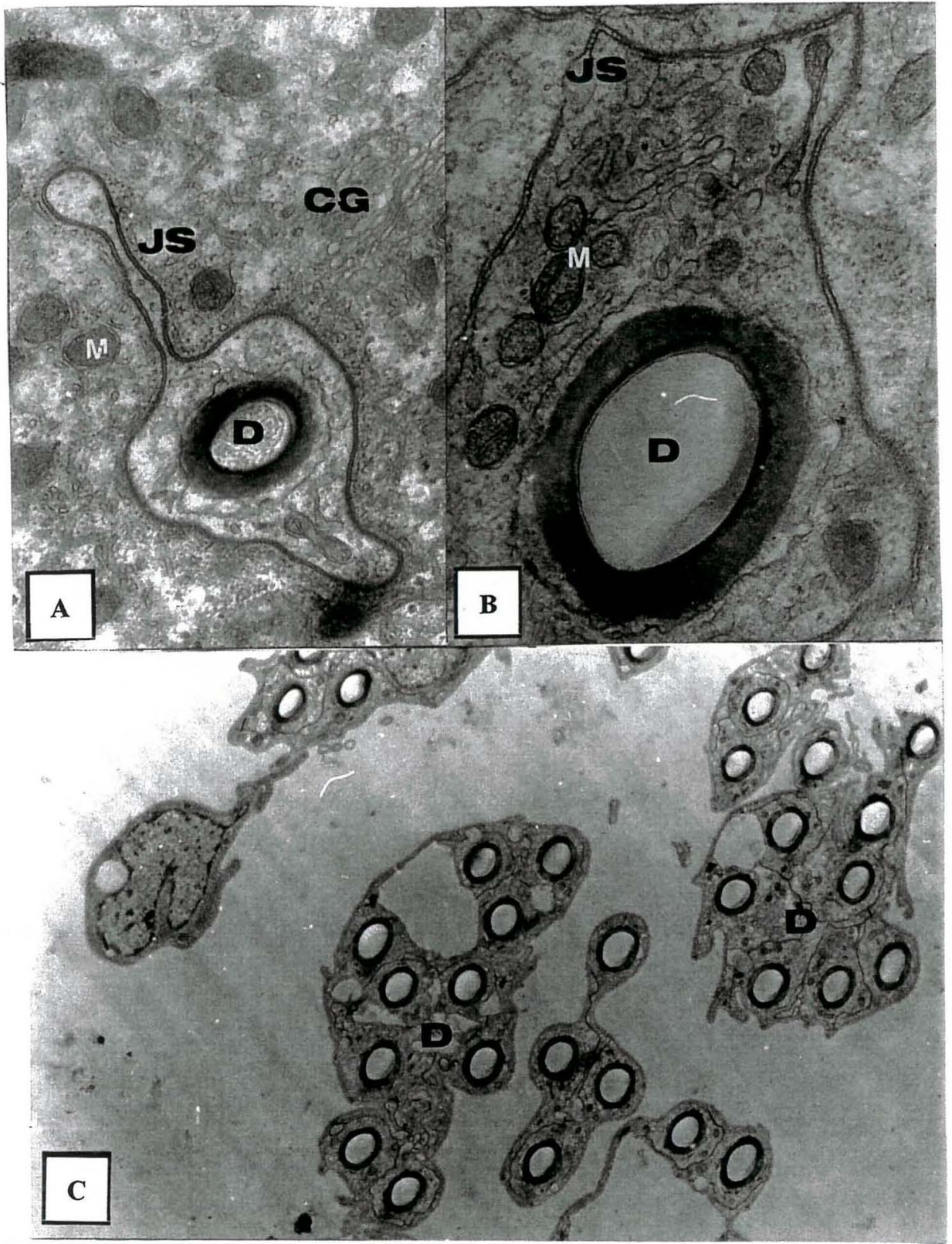

Figura 2. Atta bisphaerica. A- corte transversal do duto coletor (D). (23220x) B- corte transversal do duto coletor (D), (35260x) C- grupos de dutos coletores próximos ao reservatório. (4940x) M - mitocôndria, CG- complexo de Golgi, JS - junção septada 


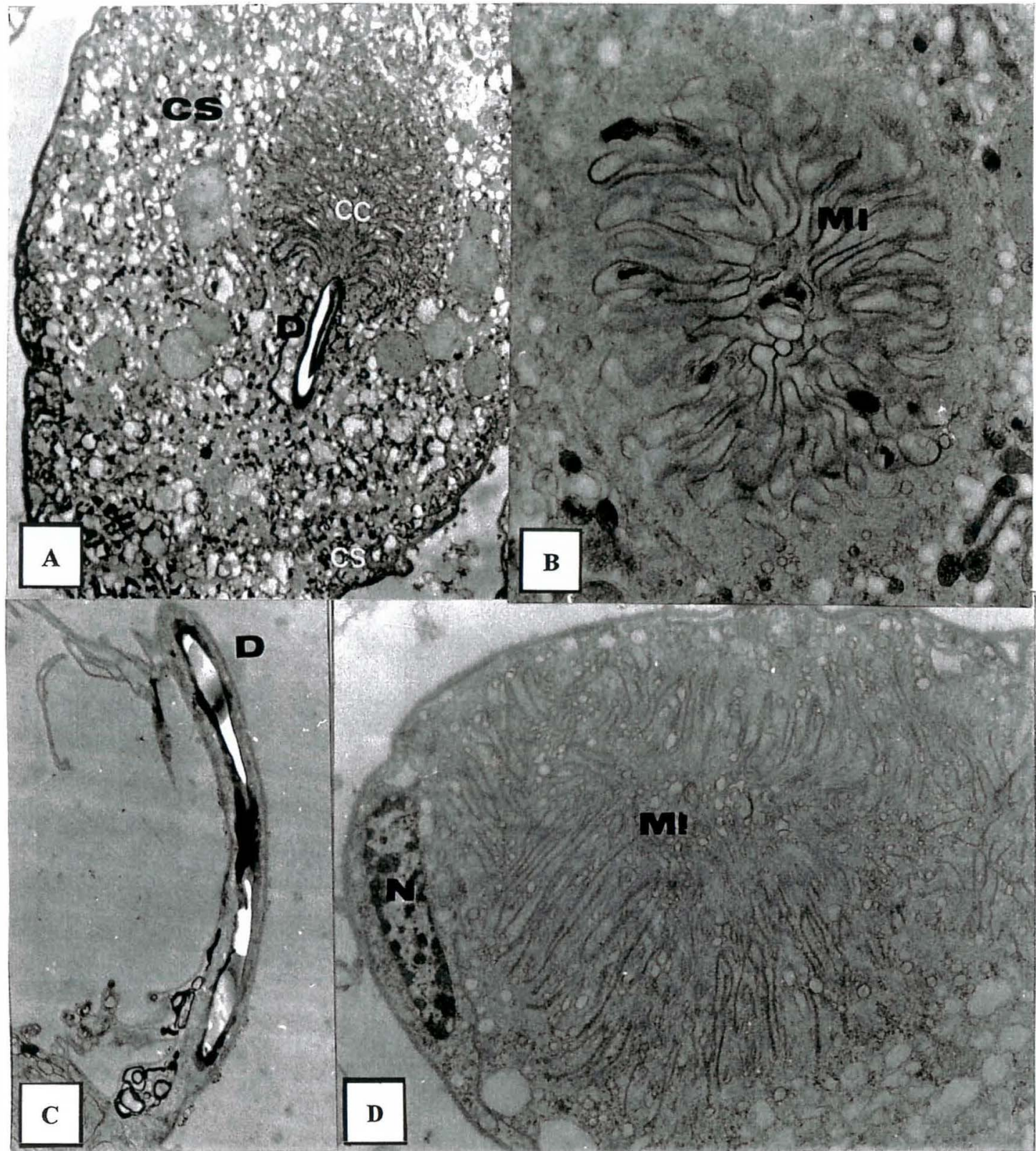

Figura 3. Atta bisphaerica. A- célula secretora (CS) mostrando corte da célula coletora (CC) e corte longitudinal do duto coletor (D). (4940x) B- detalhe de microvilosidades (MI) da célula coletora. (11390x) C - corte longitudinal do duto coletor (D). (4940x) D - célula secretora mostrando corte do núcleo (N) da célula coletora e suas microvilosidades (MI). (11390x) 


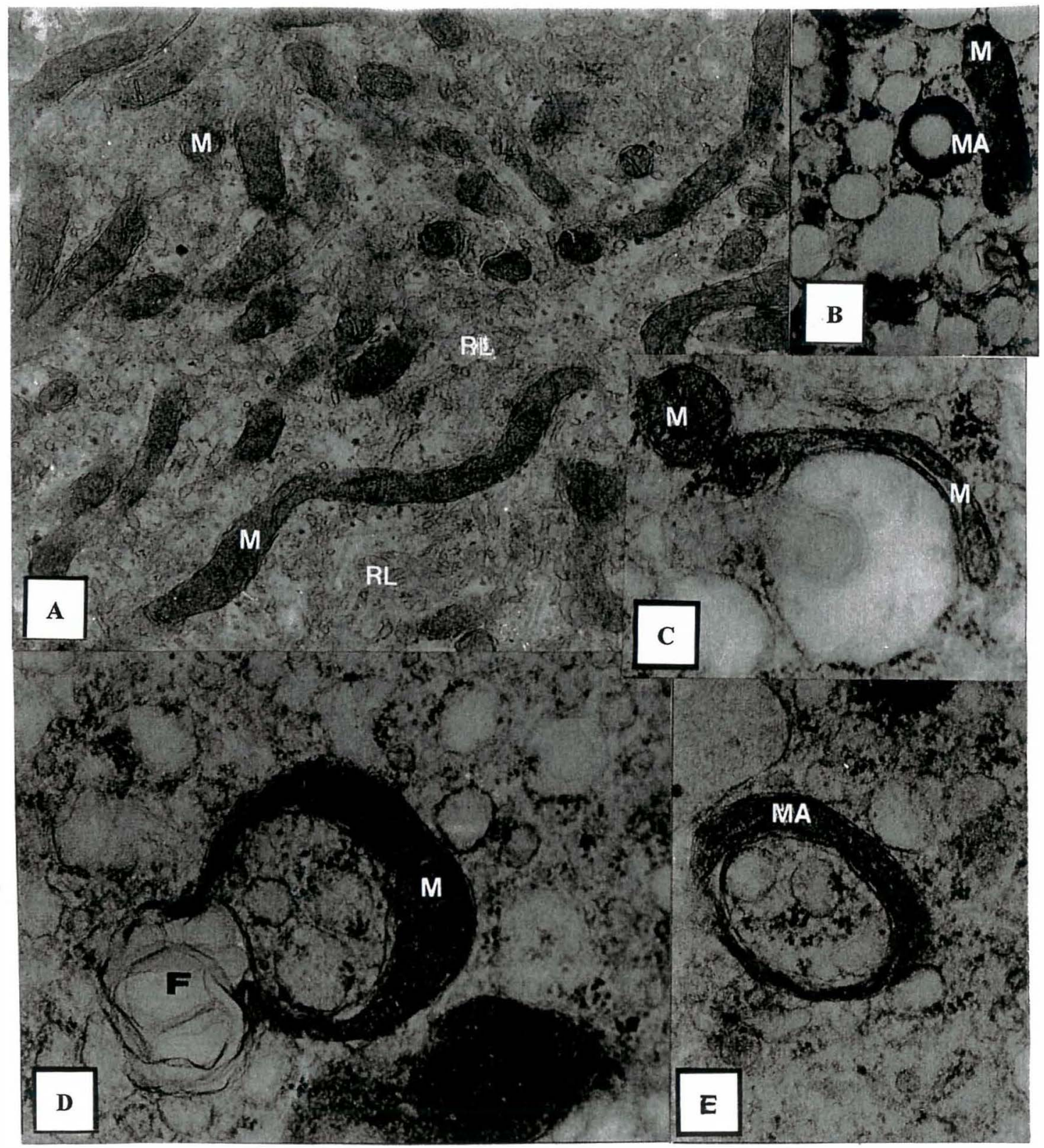

Figura 4. Tipos de mitocôndrias (M) encontradas na célula secretora de Atta bisphaerica. A- arredondadas e alongadas. (23220x) B - em anel.(MA) (8380x) C, D e E - sequência da formação das mitocôndrias em anel. Observe que parte do citoplasma é englobado por elas. (49450x) RL -retículo endoplasmático liso, F- figura mielínica. 


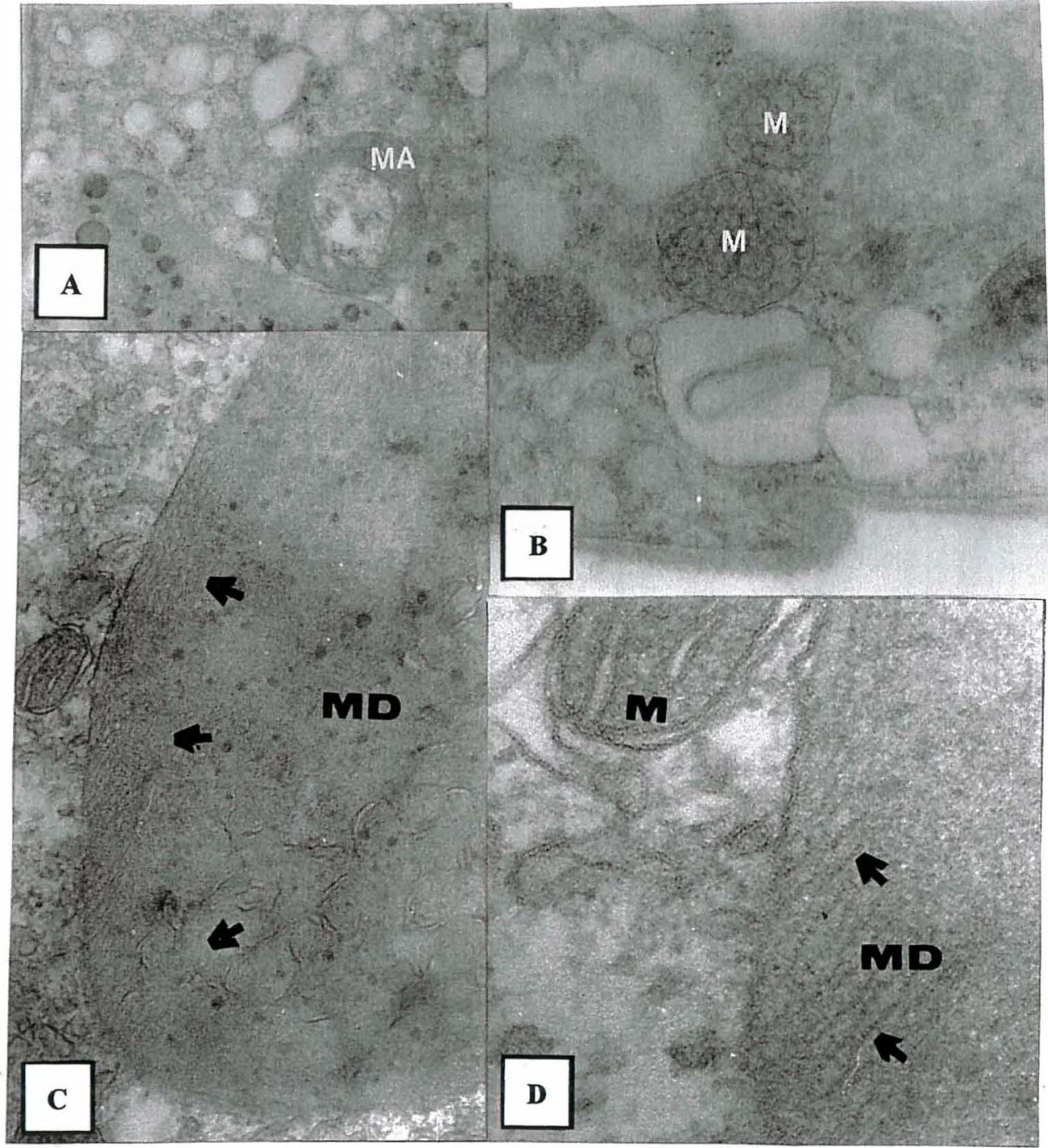

Figura 5. Tipos de mitocôndrias (M) encontradas na célula secretora de Atta bisphaerica. A- em anel. (MA) (19780x) B - arredondadas (M). Observe a presença de cristas tubulares. (36120x) C - presença de arranjos membranosos delicados (setas) no interior da denominada mitocôndria derivada (MD). (45150x) D - detalhe dos arranjos membranosos da figura anterior. (133300x) 


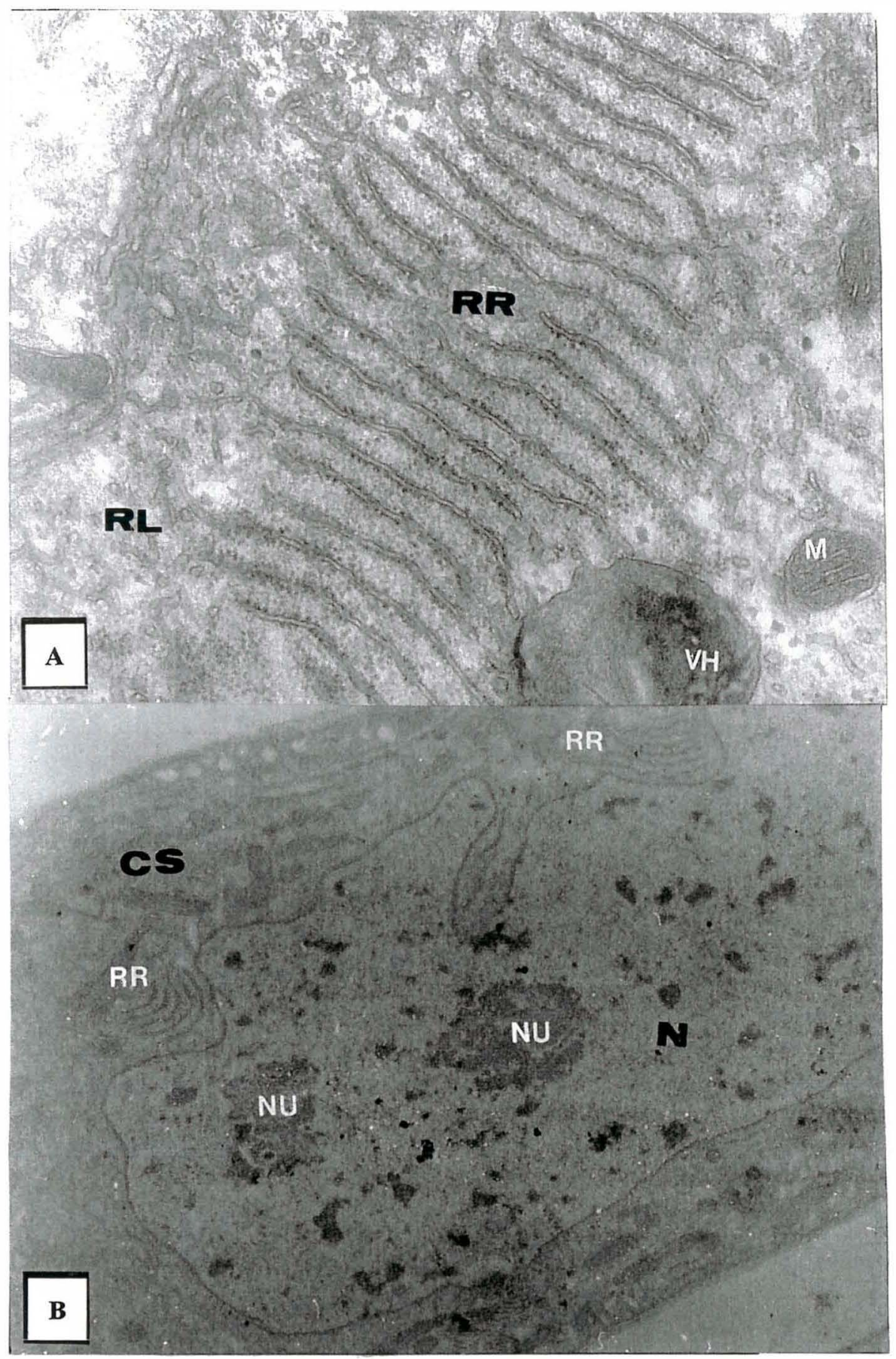

Figura 6. Atta bisphaerica. A - vista geral do citoplasma da célula secretora mostrando retículo endoplasmático liso (RL), retículo endoplasmático rugoso (RR), vacúolo heterofágico (VH) e mitocôndria (M). (35260x) B - detalhe do núcleo (N) de uma célula secretora (CS) mostrando dois nucléolos (NU) grandes e invaginações das membranas nucleares contendo retículo endoplasmático rugoso (RR). (8810x) 


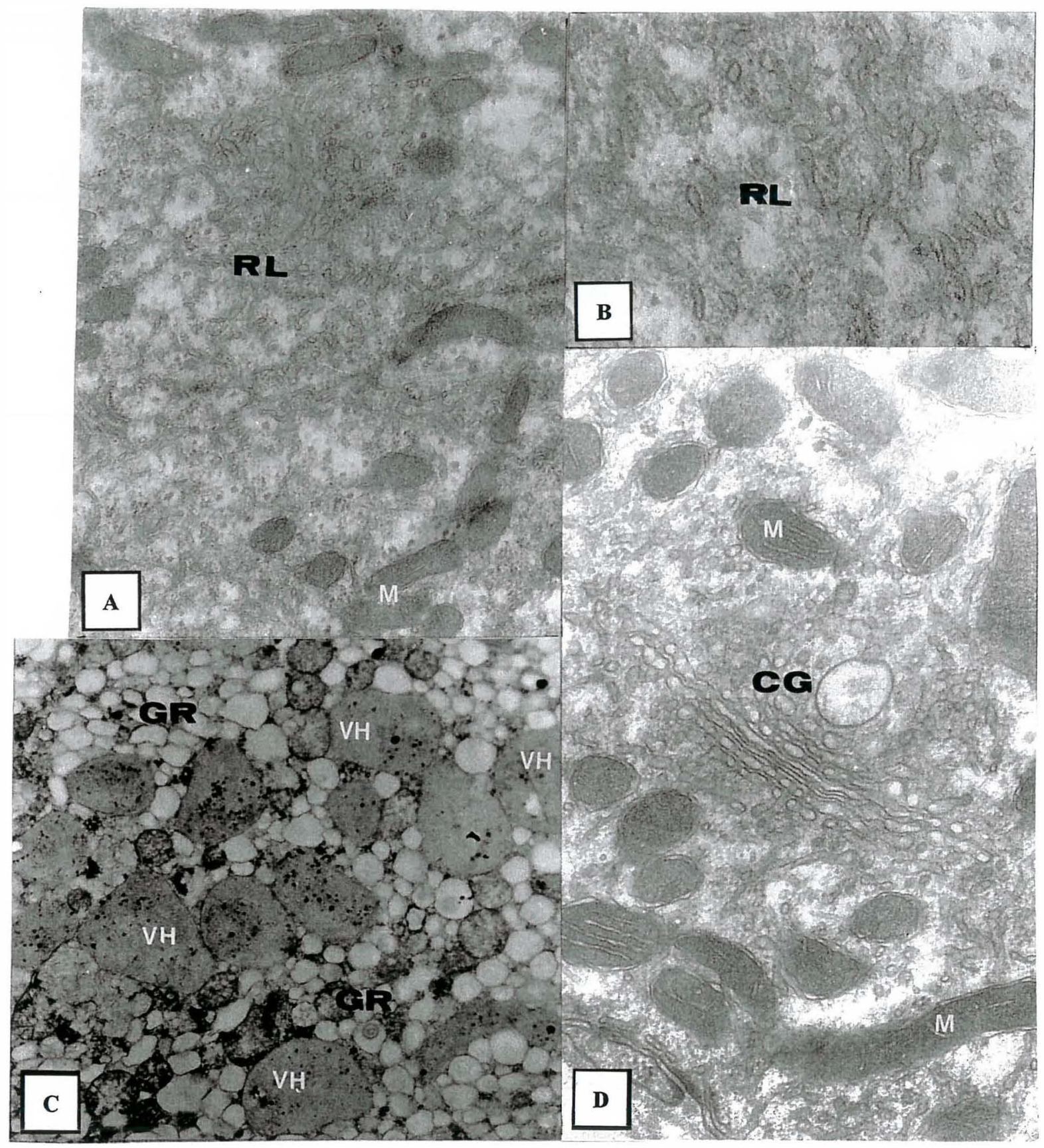

Figura 7. Citoplasma da célula secretora de Atta bisphaerica. A e B - detalhe do retículo endoplasmático liso (RL). (23220x e 58050x) C - vacúolos heterofágicos (VH) e grânulos (GR) com diferentes eletrondensidades. (8380x) D - complexo de Golgi típico (CG) com cisternas achatadas e vesículas nas extremidades circundado por um grande número de mitocôndrias (M). (35260x) 


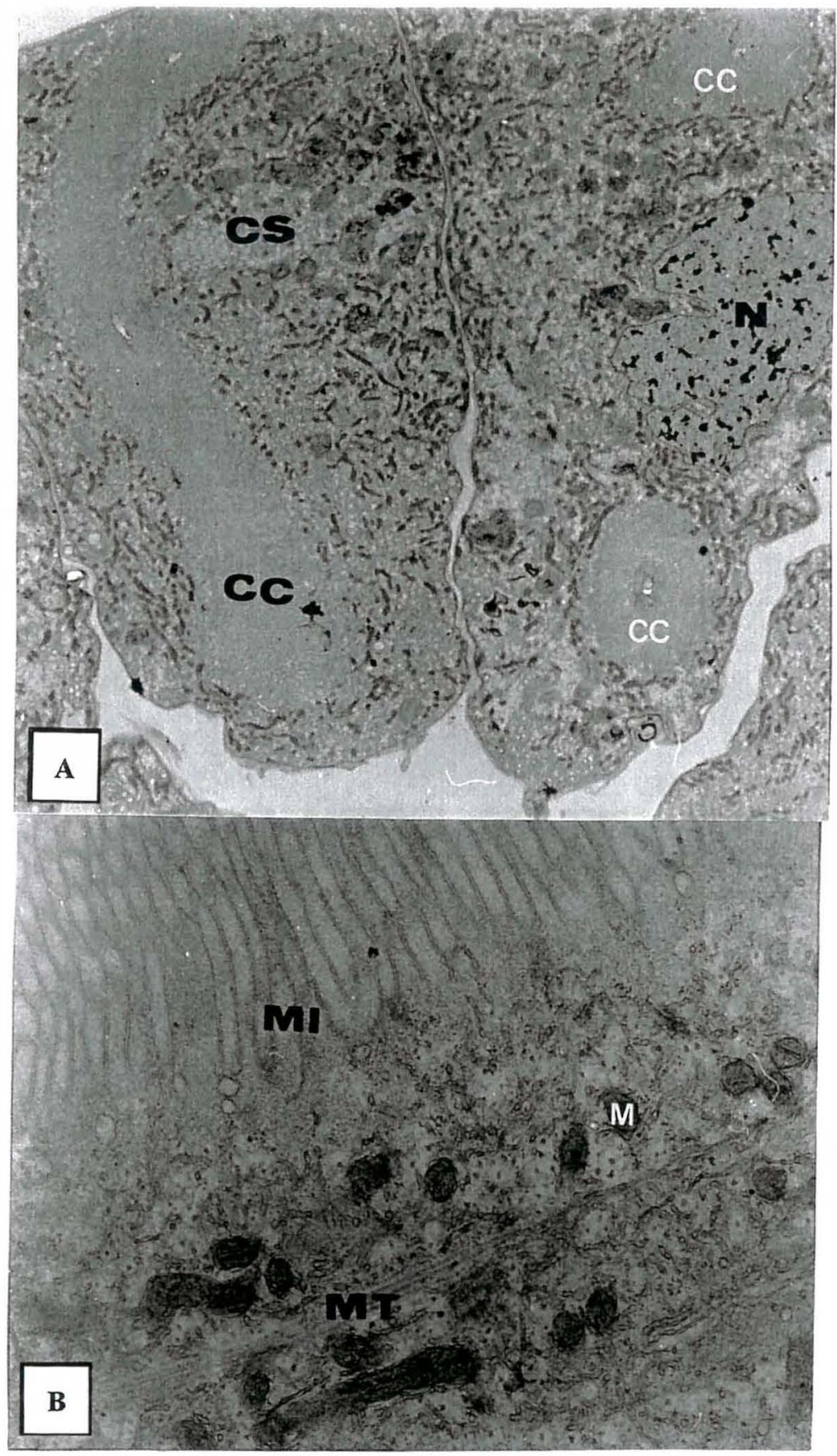

Figura 8. Atta sexdens rubropilosa. A - célula secretora típica (CS) mostrando corte do núcleo $(\mathrm{N})$ e cortes oblíquos da célula coletora (CC). (2400x) B - detalhe do citoplasma da célula secretora mostrando microvilosidades (MI) da célula coletora circundada por mitocôndrias (M). (18060x) MT- microtúbulo 


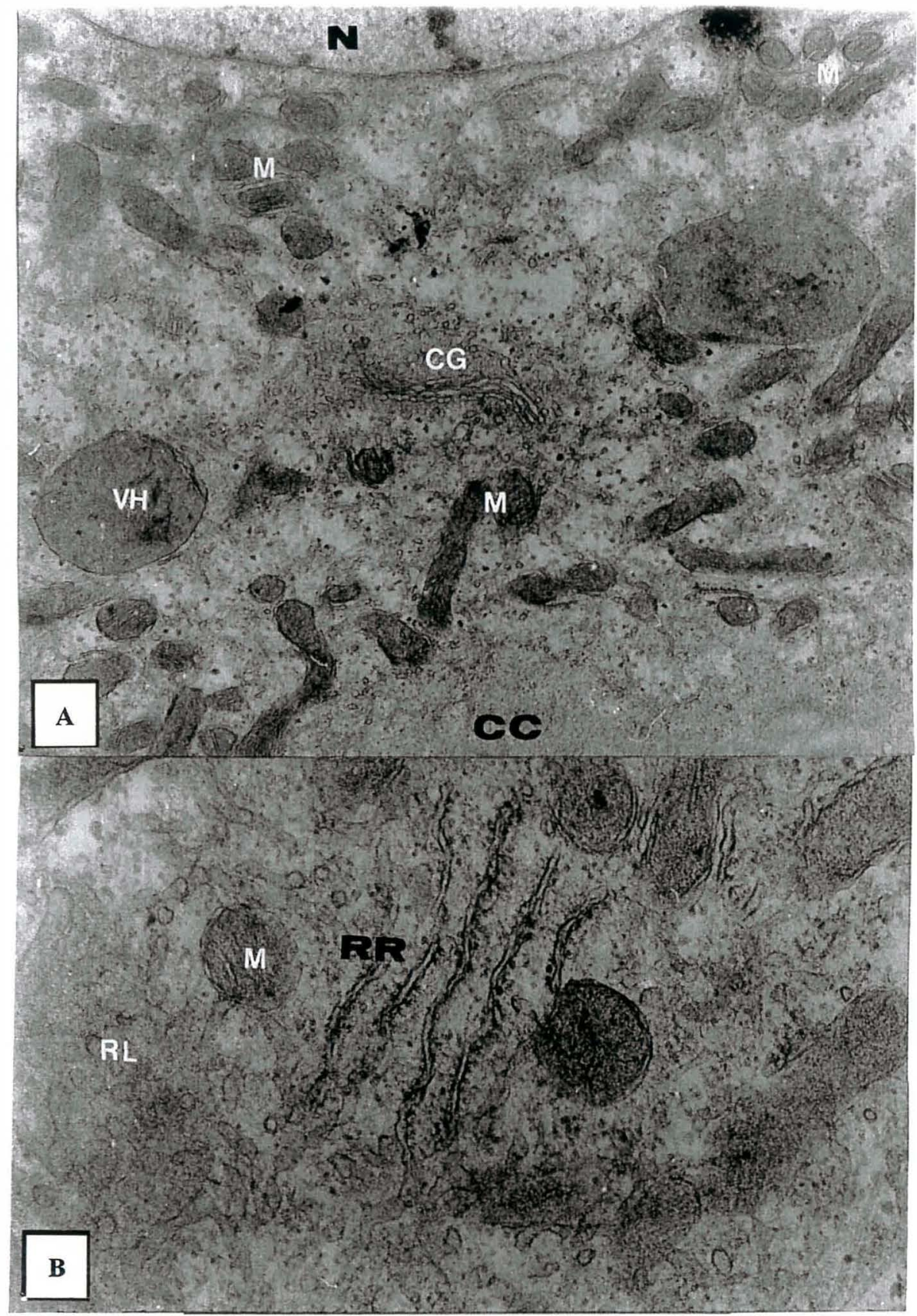

Figura 9. Detalhe do citoplasma da célula secretora de Atta sexdens rubropilosa. Anúcleo $(\mathrm{N})$, mitocôndrias $(\mathrm{M})$, complexo de Golgi (CG) típico, vacúolos heterofágicos (VH) e célula coletora (CC). (18060x) B - retículo endoplasmático liso $(R L)$, retículo endoplasmático rugoso $(R R)$ e mitocôndria (M). (45150x) 


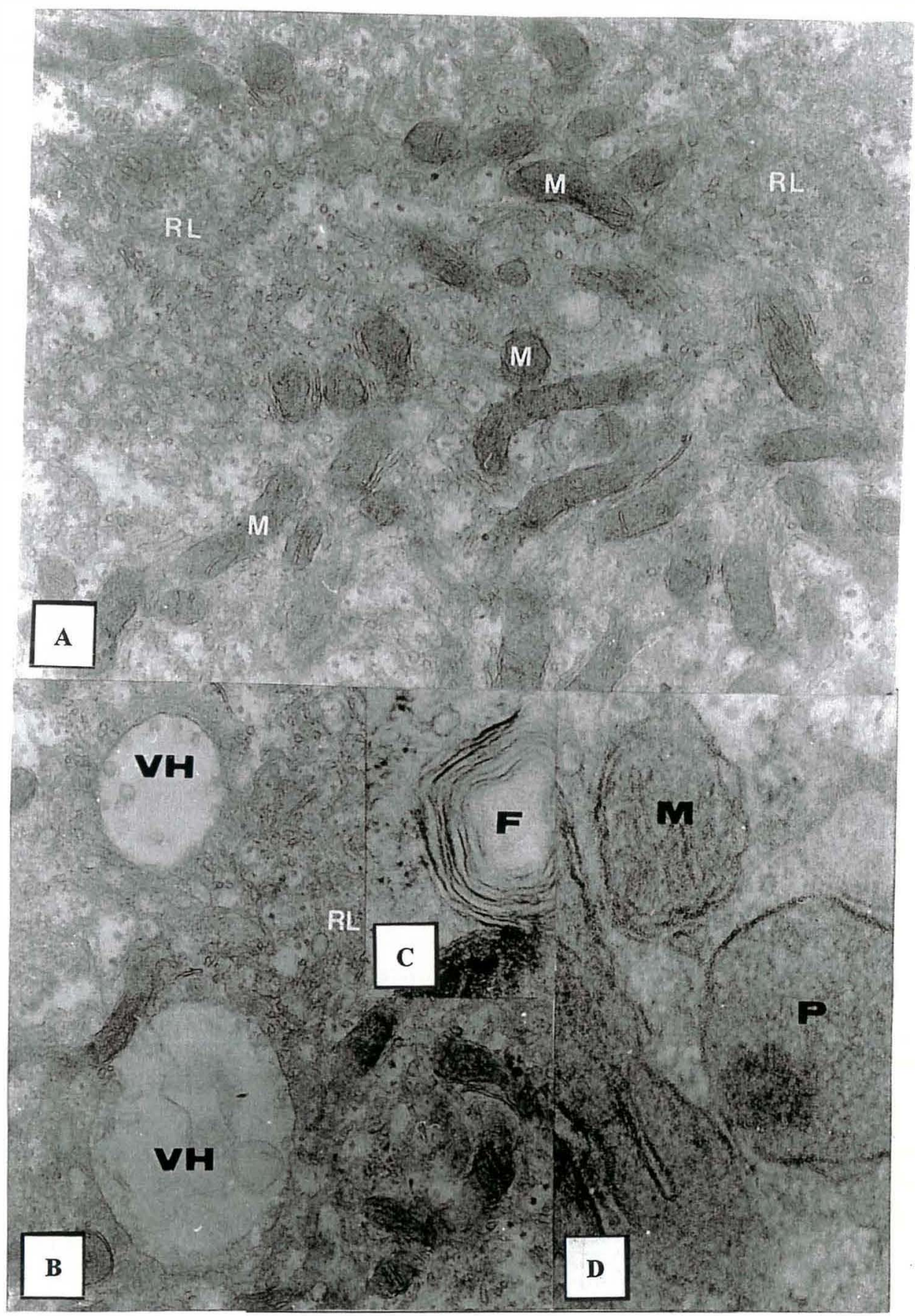

Figura 10. Detalhe do citoplasma da célula secretora de Atta sexdens rubropilosa. A e Bretículo endoplsmático liso $(\mathrm{RL})$, mitocôndrias $(\mathrm{M})$ e vacúolos heterofágicos (VH). (23220x) C - detalhe de uma figura mielínica (F). (49450x) Dperoxissomo (P) próximo a mitocôdrias (M). (92450x) 
O material no qual foi aplicada a técnica de Afzellius não mostrou qualquer evidência da presença de glicogênio no seu citoplasma.

\section{4 CONCLUSÕES}

A glândula metapleural de rainhas fecundadas de Atta bisphaerica e A. sexdens rubropilosa apresenta grande atividade de biossíntese de proteínas e lipídios.

Não há diferenças ultra-estruturais da glândula metapleural de rainhas fecundadas de Atta bisphaerica e A. sexdens rubropilosa. 


\section{COMPOSIÇÃO QUÍMICA DA SECREÇÃO DA GLÂNDULA METAPLEURAL DE Atta bisphaerica FOREL, 1908 E Atta capiguara GONÇALVES, 1944 (HYMENOPTERA: FORMICIDAE)}

\section{RESUMO}

Utilizando a técnica de cromatografia em fase gasosa e espectrometria de massas (GC-MS), a composição química da secreção metapleural de jardineiras, forrageadoras e rainha de Atta bisphaerica e forrageadoras de A. capiguara foi analisada. Na primeira espécie, além de um éster, foram encontrados ácido fenil acético, $\beta$-hidroxiácidos e hidrocarbonetos insaturados, que foram relacionados com a atividade microbiana da secreção. Diferenças qualitativas foram observadas entre as duas espécies e comparadas com a secreção de outras $A t t a$ spp. . A ausência do ácido indolacético em ambas espécies foi relacionada com desenvolvimento do fungo simbionte.

Palavras-chave: cromatografia de gases, espectrometria de massas, formigas cortadeiras, glândula exócrina 


\section{CHEMICAL COMPOSITION OF METAPLEURAL GLAND SECRETION FROM Atta bisphaerica FOREL, 1908 AND Atta capiguara GONÇALVES, 1944 (HYMENOPTERA: FORMICIDAE)}

\section{SUMMARY}

The chemical analyses of the secretions of the metapleural glands of minor workers, workers and queen of Atta bisphaerica and workers of A. capiguara were carried out by using a gas cromatography-mass spectrometry (GC-MS) technique. In $A$. bisphaerica, beside an ester, were found phenylacetic acid, $\beta$-hidroxyacids and unsaturated hidrocarbons which were related with antimicrobial activity of metapleural secretion. There were qualitative differences in the acidic composition of secretion between both species which were compared with other Atta spp. . The absence of indoleacetic acid in $A$. bisphaerica and $A$. capiguara was related with the growth of symbion fungus.

Key words: gas chromatography, exocrine gland, leaf cutter ant, mass spectrometry

\subsection{INTRODUÇÃO}

Em várias espécies de formigas a glândula metapleural produz uma secreção antibiótica que protege a superficie do corpo do inseto e seu ninho, inibindo o crescimento de bactérias (Maschwitz et al., 1970; Schildknecht \& Koob, 1971; Iizuka et al., 1979; Veal et al., 1992; Mackintosh et al., 1995; Nascimento et al., 1996), o crescimento micelial e a germinação de esporos de fungos (Maschwitz et al., 1970; Schildknecht \& Koob, 1971; Beattie et al., 1985; Beattie et al., 1986; Nascimento et al., 1996). 
Em algumas situações, onde a secreção metapleural inibiu a germinação ou diminuiu a qualidade de grãos de pólen, alguns autores procuraram relacionar o fato com algum propósito evolutivo ( Beattie et al., 1985; Peakall et al., 1990; Ramsey, 1995). Outras hipóteses, como a função de feromônio territorial (Jaffe \& Puche, 1984; Cammaerts \& Cammaerts, 1998) e feromônio de alarme (Maschwitz et al., 1970; Maschwitz, 1974; Baiocco \& Cunha, 1992), foram demonstradas e discutidas.

Veal et al. (1992) encontraram dois tipos de secreção em Myrmecia gulosa: leitosa e clara, mas não observaram diferenças nas suas propriedades microbianas. Os autores associaram a secreção leitosa, mais viscosa, à natureza lipóidea da mesma, que pode apresentar uma interação com as ceras epicuticulares do corpo das formigas, prevenindo, desse modo, epizootias dentro da colônia. Essa mesma coloração brancoleitosa foi relatada para a secreção metapleural de $A$. sexdens rubropilosa, $A$. cephalotes e Acromyrmex octospinosus (Nascimento et al., 1996).

A natureza química dos agentes antimicrobianos na secreção metapleural não tem sido claramente identificada (Mackintosh et al., 1995).

Fanfani \& Dazzini (1991) relataram vários trabalhos envolvendo a análise química dessa secreção:

- Em Atta sexdens identificaram-se os ácidos fenilacético (Maschwitz et al., 1970; Schildknecht \& Koob, 1971, 1973), indolacético (Schildknecht \& Koob, 1970, 1971, 1973), $\beta$-hidroxi-hexanóico, $\beta$-hidroxioctanóico e $D$ - $\beta$-hidroxidecanóico (mirmecacina) (Schildknecht \& Koob, 1971).

- A secreção de Myrmica laevinodis foi caracterizada pela presença dos ácidos fenilacético, D- $\beta$-hidroxidecanóico (mirmecacina) (Schildknecht \& Koob, 1971) e indolacético (Schildknecht \& Koob, 1970, 1971), sendo que os dois primeiros foram identificados também em Messor barbarıs e os dois últimos em Acromyrmex sp. (Schildknecht \& Koob, 1971).

Vários compostos fenólicos, incluindo 3-propilfenol, 3-pentilfenol, 3,4-dihidro8-hidroxi-3-metilisocumarina (meleina), 5-propilresorcinol e 5-pentilresorcinol, foram encontrados na secreção metapleural de Crematogaster difformis (Attygalle et al., 1989). 
Os resultados de Mackintosh et al. (1995) indicaram que a secreção de Myrmecia gulosa é rica em ácidos carboxílicos mas que não foram identificados.

$\mathrm{O}$ ácido fenilacético foi o principal componente detectado na secreção metapleural de operárias e soldados de Atta sexdens rubropilosa e A. cephalotes. Também foram encontrados outros ácidos como o indolacético, $\beta$-hidroxidecanóico (mirmecacina), $\beta$-hidroxi-octanóico e $\beta$-hidroxidodecanóico, sendo que os três últimos não foram observados em operárias de $A$. cephalotes (Nascimento et al., 1996). Os mesmos autores constataram a presença dos ácidos $\beta$-hidroxidecanóico e indolacético e ausência do ácido fenilacético na secreção de Acromyrmex octospinosus.

$\mathrm{O}$ ácido indolacético é um hormônio reconhecido como a principal auxina das plantas superiores, sendo utilizado como regulador de crescimento, atuando no alongamento celular (Ferri, 1986). Schildknecht \& Koob (1971) mostraram que, enquanto o ácido fenilacético inibiu o crescimento bacteriano no jardim de fungo de $A$. sexdens, o ácido indolacético manteve seu crescimento micelial. Portanto, apenas o fungo simbionte seria capaz de progredir na fundação de uma nova colônia porque ele é trazido como micélio pela rainha após o vôo nupcial. Todos os outros fungos introduzidos como esporos permaneceriam sem se desenvolver. Nascimento et al. (1996) relataram o efeito inibitório do ácido indolacético sobre algumas bactérias.

Em A. cephalotes e $A$. sexdens rubropilosa foram encontrados em média, respectivamente, 0,01 e $0,95 \mu \mathrm{g}$ de secreção/operária máxima e 0,20 e $0,95 \mu \mathrm{g}$ de secreção/soldado (Nascimento et al., 1996). Enquanto Maschwitz et al. (1970) encontraram 1,4 $\mu \mathrm{g}$ de ácido fenilacético por operária de $A$. sexdens, Nascimento et al. (1996) obtiveram $0,54 \mu \mathrm{g} /$ operária máxima e $0,82 \mu \mathrm{g} /$ soldado de $A$. sexdens rubropilosa, sugerindo que a diferença nos resultados residiu na incompleta remoção da secreção pelo método empregado.

Pequenas quantidades de certos ácidos graxos de cadeia longa têm demonstrado efeito inibitório sobre microrganismos ( Iizuka et al., 1979; Saxena \& Jain, 1989; Wang \& Johnson, 1992; Ribeiro et al., 1998 ). 
O fungo simbionte cultivado por Atta sexdens teve seu desenvolvimento fortemente inibido por uma mistura de ácidos graxos, que ao serem separados por fracionamento perderam ou diminuíram essa atividade. Provavelmente a inibição observada foi conseqüência da ação conjunta de alguns dos compostos e não de uma única substância (Ribeiro et al.,1998). O mesmo se aplica para outras secreções como, por exemplo, feromônios, onde diferentes proporções dos mesmos compostos resultam em diferentes misturas com diferentes funções em diferentes insetos (Salzemann et al., 1992).

O modo de ação da secreção metapleural sobre microorganismos tem sido pouco explorado. Wang \& Johnson (1992) relataram que ácidos graxos poli-insaturados inibem organismos através da auto-oxidação e formação de peróxidos e radicais. Em algumas bactérias a membrana citoplasmática é o primeiro sítio de ação da secreção metapleural, que provoca a perda da permeabilidade seletiva (Wang \& Johnson, 1992; Mackintosh et al., 1995).

Acredita-se que uma das prováveis causas do insucesso das inúmeras tentativas de criação de $A$. bisphaerica e $A$. capiguara, em laboratório, reside no fato de que a secreção da glândula metapleural dessas espécies não atue de forma tão eficiente, como nas demais espécies de saúvas até agora estudadas. Portanto, este trabalho teve como objetivo analisar quali-quantitativamente a composição química da secreção da glândula metapleural dessas espécies.

\section{2 MATERIAL E MÉTODOS}

O trabalho foi realizado no Laboratório de Microscopia Eletrônica do Departamento de Biologia, do Instituto de Biociências da Universidade Estadual Paulista-UNESP- Campus de Rio Claro, SP e no Departamento de Biologia de Organismos, da Universidade Simón Bolívar - Caracas, Venezuela. 


\subsubsection{Coleta de material}

Rainhas fecundadas $(25 \mathrm{~mm})$, forrageadoras $(10 \mathrm{~mm})$ e jardineiras $(3 \mathrm{~mm})$ foram coletadas em sauveiros jovens (3-4 meses, com panela única) de Atta spp. cortadoras de gramíneas, no município de Conchas, SP. O material foi identificado pela técnica de eletroforese horizontal em gel de poliacrilamida para diferenciação de espécies por meio de padrões isoenzimáticos (Augustin et al., 1998).

Forrageadoras de $A$. capiguara foram coletadas em sauveiros adultos. Não foram coletados soldados ( $15 \mathrm{~mm}$ ), pois os mesmos não foram encontrados na época de coleta.

As coletas foram efetuadas em localidades onde foi registrada a ocorrência de revoadas a partir do mês de outubro, do ano anterior, próximas ao município de Piracicaba, para facilitar o transporte e evitar o "stress" das formigas.

Todas as formigas, assim obtidas, foram encaminhadas vivas para o laboratório. No caso dos ninhos jovens, esses foram coletados integralmente (fungo + formigas) com o auxílio de enxada e colher, e acondicionados em potes plásticos de $300 \mathrm{ml}$, com tampa perfurada, permitindo assim melhor preservação do material vivo, principalmente no que diz respeito às rainhas. Do material obtido de sauveiros adultos, acondicionou-se apenas as formigas ( $\pm 50 /$ recipiente) em potes plásticos de $300 \mathrm{ml}$, com os bordos internos recobertos com vaselina líquida (faixa de $\pm 1 \mathrm{~cm}$ ) para evitar a fuga dos indivíduos.

\subsubsection{Cromatografia em fase gasosa e espectrometria de massas (GC-MS)}

A remoção da glândula e do reservatório foi feita por meio de dissecação de formigas vivas, com o auxílio de tesoura de dissecação para insetos, pinças de ponta fina e estereomicroscópio (Zeiss), porém fora de qualquer meio líquido, a seco. Os insetos foram previamente anestesiados com choque térmico a uma temperatura de aproximadamente $-20{ }^{\circ} \mathrm{C}$ e posteriormente imobilizados com alfinetes entomológicos, em placa de Petri com mistura de cera de abelha com parafina corada. Foram dissecadas 50 rainhas, 150 forrageadoras e 200 jardineiras de cada espécie. 
Após a dissecação de cada indivíduo, suas glândulas e reservatórios (acompanhados de restos de tegumento, músculos e corpos gordurosos) foram transferidas para frascos de vidro (Hewlett-Packard-2 $\mathrm{ml}$ ) contendo $0,5 \mathrm{ml}$ de hexano P.A. $\left[\mathrm{CH}_{3}\left(\mathrm{CH}_{2}\right)_{4} \mathrm{CH}_{3}\right]$. Cada frasco foi lacrado com tampa de alumínio, revestida com septo de borracha para evitar vazamentos, utilizando-se um lacrador (Hewlett-Packard). Para neutralizar a interferência de contaminantes, na análise dos resultados, após o processamento das amostras, foi montado um frasco contendo apenas o solvente (prova em branco) e frascos contendo solvente mais restos de tegumento, músculos e corpos gordurosos (uma amostra/casta/espécie).

Todos os frascos foram devidame nte identificados e enviados para a Universidade Simón Bolívar (Caracas-Venezuela), onde foram efetuadas as análises cromatográficas.

Por meio de fluxo moderado de nitrogênio, os extratos foram concentrados até que seus volumes fossem reduzidos a, aproximadamente, $20 \mu \mathrm{l}$. Seguiu-se o mesmo procedimento com o solvente puro. Com o objetivo de derivatizar os hidroxiácidos presentes foi necessário acrescentar aproximadamente $500 \mu \mathrm{l}$ de $\mathrm{BF}_{3} / \mathrm{Metanol}$, aquecer a $60{ }^{\circ} \mathrm{C}$ durante 5 minutos, em seguida, resfriar e acrescentar $500 \mu$ de água para separar a fase orgânica. Desses extratos concentrados, frações de $1 \mu l$ foram seqüencialmente injetadas no sistema cromatográfico em fase gasosa (Perkin Elmer Autosystem 2000) composto de espectròmetro de massas (Qmass-910/GC-MS) e integrador (Qmass-910) com sistema de análise de dados. Todas as variáveis instrumentais do sistema cromatográfico foram ajustadas de acordo com Nascimento et al. (1996), sendo a identificação dos compostos feita por comparação direta à biblioteca de compostos obtida junto à NIST-EPA-MSCD (1994) e confirmadas na literatura especializada.

\section{3 RESULTADOS E DISCUSSÃO}

Todos os exemplares obtidos de sauveiros novos foram identificados como $A$. bisphaerica. 
A secreção da glândula metapleural de Atta capiguara e A. bisphaerica apresentou coloração branco-leitosa similarmente ao que foi observado por Veal et al. (1992) e Nascimento et al. (1996)

Com relação à composição química da secreção metapleural, em $A$. capiguara identificou-se apenas o ácido fenilacético, enquanto em $A$. bisphaerica foram encontrados os ácidos fenilacético, $\beta$-hidroxidecanóico (mirmecacina) e $\beta$ hidroxidodeconóico (Tabela 1). Em ambas espécies, verificou-se a ausência do ácido indolacético, um dos componentes encontrado na secreção de $A$. sexdens rubropilosa (Schildknecht \& Koob, 1970, 1971, 1973; Nascimento et al., 1996) e que segundo Schildknecht \& Koob (1971) tem importante função no crescimento micelial do fungo simbionte.

Dessa forma, a ausência do ácido indolacético na composição da secreção metapleural de $A$. capiguara e $A$. bisphaerica pode explicar a pouca quantidade de fungo e a grande quantidade de material vegetal cortado encontrados nos ninhos dessas espécies quando comparados com o existente em ninhos de A. sexdens rubropilosa.

Tabela 1. Composição química da secreção metapleural de diferentes castas de Atta bisphaerica e forrageadoras de $A$. capiguara.

\begin{tabular}{lcccr}
\hline \multirow{2}{*}{$\begin{array}{c}\text { Componentes da secreção } \\
\text { (ng/ indivíduo) }\end{array}$} & Atta capiguara & \multicolumn{3}{c}{ Atta bisphaerica } \\
\cline { 2 - 4 } & Forrageadora & Jardineira & Forrageadora & Rainha \\
\hline Ácido fenilacético & 46,7 & 42,5 & 50,0 & $11.980,0$ \\
Ácido $\beta$-hidroxidecanóico & 0,0 & 17,5 & 20,0 & $2.870,0$ \\
Ácido $\beta$-hidroxidodecanóico & 0,0 & 2,5 & 30,0 & $2.100,0$ \\
Pentacoseno & 0,0 & 10,0 & 47,0 & 340,0 \\
Heptacoseno & 0,0 & 42,5 & 127,0 & 920,0 \\
Nonacoseno & 0,0 & 0,0 & 0,0 & 210,0 \\
Butilpalmitato & 0,0 & 0,0 & 0,0 & 260,0 \\
\hline
\end{tabular}

Provavelmente a presença de penta, hepta e nonacoseno na secreção de $A$. bisphaerica (Tabela 1) auxilia o ácido fenilacético na proteção do corpo das formigas 
por meio de sua atividade antimicrobiana, uma vez que hidrocarbonetos não são facilmente digeridos pela maioria dos microrganismos (Bagnères \& Morgan, 1991).

Segundo Cabrera ${ }^{1}$, o butilpalmitato pode ser algum intermediário químico derivado do ácido palmítico que está sempre presente em todos os tecidos, de todos os insetos com que se tem trabalhado. Sua presença pode estar relacionada com algum processo de biossíntese e o fato de ser encontrado apenas na rainha é atribuído ao maior tamanho desse indivíduo.

Com os resultados obtidos da análise quali-quantitativa da secreção metapleural de forrageadoras de $A$. capiguara não é possível inferir a respeito das demais castas da mesma espécie. Entretanto, se for feita uma analogia com as castas de A. bisphaerica, apenas a presença do ácido fenilacético na secreção de $A$. capiguara talvez não seja suficiente para manter o bom desenvolvimento do fungo e proteger os indivíduos da colônia, fazendo com que essa espécie torne-se menos competitiva do que outras saúvas encontradas na mesma região.

Quantitativamente os resultados obtidos para forrageadoras de $A$. capiguara e $A$. bisphaerica com relação ao ácido fenilacético diferiram dos relatados por Maschwitz et al. (1970) para $A$. sexdens e Nascimento et al. (1996) para $A$. sexdens rubropilosa e $A$. cephalotes, demostrando a existência de uma grande variabilidade entre espécies.

Embora com tamanho très vezes menor do que as forrageadoras, as jardineiras de A. bisphaerica produziram quantidade semelhante de ácido fenilacético por indivíduo (Tabela 1). Esse fato é justificado pela função primária que essa casta desempenha dentro da colônia e pode estar associado aos resultados obtidos e discutidos no Capítulo 3 deste trabalho.

${ }^{1}$ CABRERA. A.C. G. Comunicação pessoal. 2000. 


\subsection{CONCLUSÕES}

O ácido fenilacético é o único componente da secreção metapleural de forragedoras de Atta capiguara.

A secreção metapleural de forragedoras de A. capiguara, jardineiras, forragedoras e rainhas de $A$. bisphaerica não contém ácido indolacético 


\section{CONCLUSÕES GERAIS}

Não há diferenças ultramorfológicas interespecifica da glândula metapleural de jardineiras, forrageadoras, soldados e rainhas de Atta bisphaerica, A. capiguara e $A$. sexdens rubropilosa.

O tamanho da glândula metapleural aumenta à medida que aumenta o tamanho do individuo, sendo que em rainhas ela é expressivamente maior que nas demais castas.

As características ultramorfológicas da glândula metapleural de $A$. bisphaerica e A. capiguara não mostram qualquer evidência que possa ser correlacionada com $\mathrm{o}$ insucesso da criação destas espécies em laboratório.

Não há diferenças ultra-estruturais da glândula metapleural de rainhas fecundadas de Atta bisphaerica e A. sexdens rubropilosa.

A glândula metapleural de rainhas fecundadas de Atta bisphaerica e A. sexdens rubropilosa apresenta grande atividade de biossintese de proteinas e lipidios.

O ácido fenilacético é o único componente da secreção metapleural de forragedoras de Atta capiguara.

A secreção metapleural de forragedoras de A. capiguara, jardineiras, forragedoras e rainhas de $A$. bisphaerica não contém ácido indolacético 


\section{REFERÊNCIAS BIBLIOGRÁFICAS}

AMANTE, E. Influência de alguns fatores microclimáticos sobre a formiga saúva Atta laevigata ( F. Smith, 1858), Atta sexdens rubropilosa Forel, 1908, Atta bisphaerica Forel, 1908, e Atta capiguara Gonçalves, 1944 (Hymenoptera, Formicidae), em formigueiros localizados no Estado de São Paulo. Piracicaba, 1972. 175p. Tese (Doutorado) - Escola Superior de Agricultura "Luiz de Queiroz", Universidade de São Paulo.

ANGUS, C.J.; JONES, M.K.; BEATTIE, A.J. A possible explanation for size differences in the metapleural glands of ants (Hymenoptera: Formicidae). Journal of Australian Entomological Society, v.32, n.1, p. 73-77, 1993.

ANJOS, N. dos ; SANTANA. D. L. Q. Alterações deletérias no comportamento de Atta laevigata (F. Smith) e Atta sexdens rubropilosa Forel (Hymenoptera: Formicidae), causadas por folhas de Eucalvptus spp. Anais da Sociedade Entomológica do Brasil, v. 23, n. 1, p. 25-30, 1994.

ATTYGALLE, A.B.; SIEGEL, B.; VOSTROWSKY, O.; BESTMANN, H.J.; MASCHWITZ. U. Chemical composition and funtion of metapleural gland secretion of the ant, Crematogaster deformis Smith (Hymenoptera: Myrmicinae). Journal of Chemical Ecology, v. 15. n. 1, p. 317-328, 1989. 
AUGUSTIN, E.; LOECK, A.E.; GUSMÃO, L. G. de; GRUTZMACHER, D.D. Identificação de formigas cortadeiras do gênero Acromyrmex através de padrões isoenzimáticos. In: CONGRESSO BRASILEIRO DE ENTOMOLOGIA, 17., Rio de Janeiro, 1998. Resumos. Rio de Janeiro: UFRRJ, 1998. p.873.

BAGNĖRES, A.; MORGAN, E. The postpharyngeal glands and the cuticle of Formicidae contain the same characteristic hydrocarbons. Experientia, v.47, p. 106-111, 1991.

BAIOCCO, L.M.; CUNHA, M.S. Histologia das glândulas exócrinas em rainhas de Monomorium pharaonis (Linneaus, 1758) (Hymenoptera, Formicidae). Naturalia, v.17, p. 139-152, 1992.

BEATTIE, A.J.; TURNBUll, C.; HOUGH,T.; JOBSON, S.; KNOX, R.B. The vunerability of pollen and fungal spores to ant secretions: evidence and some evolutionary implications. American Journal of Botany, v. 72, n. 4, p. 606-614, 1985.

BEATTIE, A.J.; TURNBULL, C.; HOUGH,T.; KNOX, R.B. Antibiotic production: a possible funtion for the metapleural glands of ants (Hymenoptera: Formicidae). Annals of the Entomological Society of America, v. 79, n. 3, p. 448-450, 1986.

BENTO, J. M. S.; DElla LUCiA, T. M. C.; MUChOVEJ, R. M. C.; VILELA, E. F. Influência da composição química e da população microbiana de diferentes horizontes do solo no estabelecimento de sauveiros iniciais de Atta laevigata (Hymenoptera : Formicidae ) em laboratório. Anais da Sociedade Entomológica do Brasil, v. 20, n. 2. p. 307-317, 1991. 
BILLEN, J.P.J.; VAN BOVEN, J.K.A. The metapleural gland in Old World army ants: a morphological and ultrastructural description (Hymenoptera: Formicidae). Revue Zoologie Africane, v. 101, p. 31-41, 1987.

BOT, A.N.M.; BOOMSMA,.J.J. Variable metapleural gland size-allometries in Acromyrmex leafcutter ants (Hymenoptera: Formicidae). Journal of the Kansas Entomological Society, v.69, n.4, p. 375-383, 1996. (Suppl.)

BRANCHER, N. Avaliação eletroforética e morfológica do fungo cultivado pelas formigas cortadeiras dos gêneros Atta e Acromyrmex. Pelotas, 1993. 58 p. Dissertação. (M.S.) Faculdade de Agronomia “Eliseu Maciel”, Universidade Federal de Pelotas.

BROWN, A.; HAMLTON, J. Indole-3-ethanol produced by Zygorrhyncus moelleri, na indole-3-acetic acid analogue with antifungal activity. Myrcological Research, v. 96, p. 71-74, 1992.

BROWN, W. An hypothesis concerning the funtion of the metapleural gland in ants. American Naturalist, v. 102, p. 188-191, 1968.

CAETANO, F.H. Morfologia comparada do trato digestivo de formigas da subfamilia Myrmicinae (Hymenoptera: Formicidae). Papéis Avulsos de Zoologia. v.35, n.23, p.257-305, 1984. 
CAETANO, F.H. Aspectos ultramorfológicos. ultra-estruturais e inzimológicos da glândula pós-faríngea de Dinoponera australis (Formicidae: Ponerinae). Rio Claro, 1998. 136p. Tese (Livre-Docência) - Instituto de Biociências, Universidade Estadual Paulista "Júlio de Mesquita Filho".

CAMMAERTS, M.C.; CAMMAERTS, R. Marking of nest entrance vicinity in the ant Pheidole pallidula (Formicidae, Myrmicinae). Behavioural Processes, v.42, n.1, p.19$31,1998$.

DELLA LUCIA, T. M. C. (Ed.) As formigas cortadeiras. Viçosa: Folha de Viçosa, 1993. $262 \mathrm{p}$.

FALCO, J.R.. Comparação ultra-estrutural entre glândulas pós-faríngeas de Camponotus rufipes (Hymenoptera: Formicidae) parasitadas e não parasitadas por nematóides. Rio Claro, 1992. 70p. Monografia (Graduação) - Instituto de Biociências, Universidade Estadual Paulista "Júlio de Mesquita Filho".

FANFANI, A.; DAZZINI, M.V. Le glandole metatoraciche di Crematogaster striatula (Hymenoptera. Formicidae. Myrmicinae). Fragmenta Entomologica, v. 23, n. 1. p.191-200, 1991 .

FERRI, M.G. (Coord.) Fisiologia Vegetal. 2. ed. São Paulo: E.P.U., 1986. 2v., 401 p. 
FORTI, L. C. Ecologia da saúva Atta capiguara Gonçalves, 1944 (Hymenoptera: Formicidae) em pastagem. Piracicaba, 1985. 235p. Tese (Doutorado) - Escola Superior de Agricultura “Luiz de Queiroz”, Universidade de São Paulo.

FORTI, L. C.; ICHINOSE, K. Expansão de Atta capiguara Gonçalves, 1944 (Hymenoptera. Formicidae) para o norte do Estado do Paraná e os problemas ocasionados. In : INTERNATIONAL SYMPOSIUM ON PESTS ANTS, 9.; ENCONTRO DE MIRMECOLOGIA. 11., Belo Horizonte,1993. Anais. Belo Horizonte: UFV, 1993. p.16.

HEBling, M. J. A.; MAROTI, P. S.; BUENO, O. C.; SILVA, O. A.; PAGNOCCA, F. C. Efeito da folhas de Ipomoea batatas (batata doce) no desenvolvimento de formigueiros de Atta sexdens rubropilosa Forel.1908, em laboratório. In: CONGRESSO BRASILEIRO DE ENTOMOLOGIA. 14., Piracicaba, 1993. Resumos. Piracicaba: FEALQ, 1993. p. 230.

HOLLDOBLER, B.; ENGEL-SIEGEL, H. On the metapleural gland of ants. Psyche, v. 91, n. 3/4. p. 201-224, 1984.

HOLLDOBLER,B., WILSON, E. The ants. Cambridge: Belknap Press of Harvard University Press. 1990. 732p. 
IIZUKA, T.; IWADARE, T.; ORITO, K. Antibacterial activity of myrmicacin a compound in the secretion of South American leaf-cutting ant Atta sexdens and related compounds on pathogenic bacteria in silkworm larvae, Streptococcus faecalis AD-4. Journal of Faculty of Agriculture, v. 59, p. 262-266, 1979.

JAFFE, K; PUCHE, H. Colony-specific territorial marking with the metapleural gland in the ant Solenopsis geminata (Fabr.). Journal of Insect Physiology, v. 30, n. 4, p. 265 $270,1984$.

JURUENA, L. F.; CACHAPUZ, L. M. M. Espécies de formigas cortadeiras ocorrentes no Estado do RS. IPAGRO Informa. n.23, p. 18-24, 1980.

LOECK, A. E. Efeito de novas substâncias visando o controle das saúvas de Atta spp. (Hymenoptera: Formicidae). Piracicaba. 1982. 57p. Dissertação (Mestrado) - Escola Superior de Agricultura "Luiz de Queiroz", Universidade de São Paulo.

LOECK, A. E.; ROSENTHAL. M. d'A.; GUSMÃO, L. G. de. Mini-formigueiro: método de criação de formigas cortadeiras na ausência da rainha. Anais da Sociedade Entomológica do Brasil, v. 23, n. 2, p. 359-362, 1994.

MACKINTOSH, J.A.; FLOOD. J.A.; VEAL, D.A.: BEATTIE, A.J. Increase in levels of microbiota recoverable from male and larval Myrmecia gulosa (Fabricius) (Hymenoptera: Formicidae) following segregation from worker ants. Australian Journal of Entomology, v. 38, n. 2, p. 124-126. 1999. 
MACKINTOSH, J.A.; TRIMBLE, J.E.; JONES, M.K.; KARUSO, P.H.; BEATTIE, A.J.; VEAL, D.A. Antimicrobial mode of action of secretions from the metapleural gland of Myrmecia gulosa (Australian bull ant). Canadian Journal of Microbiology, v.41, n.2, p. 136-144, 1995.

MASCHWITZ, U. Vergleichende Untersuchungen zur Funktion der Ameisenmetathorakalddrüse. Oecologia, v.16, n. 4, p. 303-310, 1974.

MASCHWITZ, U.; KOOB, K.; SCHILDKNECHT, H. Ein Beitrag zur Funktion der Metapleuraldrüse der Ameisen. Journal of Insect Physiology, v. 16, p. 387-404, 1970.

NASCIMENTO, R.R. do; SCHOETER, E.; MORGAN, E.D.; BILLEN,J.; STRADLING, D.J. Chemistry of metapleural gland secretions of three attine ants, Atta Sexdens rubropilosa, Atta cephalotes, and Acromyrmex octospinosus (Hymenoptera: Formicidae). Journal of Chemical Ecolology, v. 22, n. 5, p. 987-1000, 1996.

NIST/ EPA/ NIH - CD-ROM: Mass spectral database, version 4.5. National Institute of Standards and Technology, 1994.

NOIROT, C.; QUENNEDEY, A. Fine structure of insect epidermal glands. Annual Review of Entomology, v. 19, p. 61-80, 1974.

PEAKALL, R.; ANGUS, C.J.; BEATTIE, A.J. The significance of ant and plant traits for ant pollination in Leporella fimbriata. Oecologia, v. 84, p. 457-460, 1990. 
PRECETTI, A.A.C.M.; NASATO, A.C.M; BELTRAME,G.J.; OLIVEIRA, J.E.; PALINI JR., M. Perdas de produção em cana-de-açúcar, causadas pela saúva-mata-pasto, Atta bisphaerica. Boletim Técnico Copersucar, v. 42, p. 25-30, 1988.

RAMSEY, M. Ant pollination of the perennial herb Blandfordia grandiflora (Liliaceae). Oikos, v.74, n.2, p.265-272. 1995.

RIBEIRO, S.B.; PAGNOCCA, F.C.; VICTOR, S.R.; BUENO, O.C.; HEBLING, M.J.; BACCI JR., M.; SILVA, O.A.; FERNANDES. J.B.; VIEIRA, P.C.; SILVA, M.F.G. Activity of sesame leaf extracts against the symbiotic fungus of Atta Sexdens L. Anais da Sociedade Entomológica do Brasil, v.27, n.3, p.421-426, 1998.

SALZEMAN, A.; NAGNAN, P.: TELlIER, F.; JAFFE, K. The leaf-cutting ant Atta laevigata marks its Territory with colony-specific Dufours gland secretion. Journal of Chemical Ecolology, v. 18, p. 183-196, 1992.

SAXENA. V.; JAIN, S. Thevetia peruviana kernel oil: A potential bactericidal agent. Fitoterapia, v. 61, p. 348-349. 1990.

SCHILKNECHT, H.; KOOB, K. Myrmicacin, the first insect herbicide. Angewandte Chemie, v. 10, n. 2. p. 124-125. 1971. 
SCHOETERS, E.; BILLEN, J. Anatomy and fine structure of the metapleural gland in Atta (Hymenoptera, Formicidae). Belgian Journal of Zoology, v. 123, n. 1, p. 67-75, 1993.

SCHOETERS, E.; BILLEN, J. Morphological and ultrastructural study of metapleural gland in Diacamma (Hymenoptera, Formicidae). In: EUROPEAN CONGRESS OF SOCIAL INSECTS, 1., Leuven, 1991. Proceedings. Leuven: Leuven University Press, 1992. p.239-247.

SILVEIRA NETO, S.; VENDRAMIM, J. D.; CERIGNONI, J.A. Não-preferência de Atta sexdens rubropilosa Forel. 1908 por espécies de Eucalyptus. In: CONGRESSO BRASILEIRO DE ENTOMOlOGIA, 14., Piracicaba, 1993. Resumos. Piracicaba: FEALQ, 1993. p. 417.

TULLOCH, G.S.; SHAPIRO, J.E.; HERSHENOV, B. The ultrastructure of the metasternal glands of ants. Bulletin of Brooklyn Entomological Society, v. 57, p. 91-101, 1962.

VEAL, D.A.; TRIMBLE, J.E.: BEATTIE, A.J. Antimicrobial properties of secretions from the metapleural gland of Myrmecia gulosa (Australian bull ant). Journa of Applied Bacteriology, v.72, p. 188-194, 1992.

VILELA, E. F. Evolução do controle das formigas cortadeiras. In: ENCONTRO DE MIRMECOLOGIA. 12.. São Leopoldo. 1995. Anais. São Leopoldo: UNISINOS, 1995. p.47-51. 
WANG, L.; JOHNSON, E. Inhibition of Listeria monocytogenes by fatty acids and monoglycerides. Applied Environmental Microbiology, v. 58, p. 624-629, 1992.

ZARA, F.J. Caracterização morfo-histológica, histoquímica e ultra-estrutural da porção secretora da glândula salivar do quarto estágio larval de Neoponera villosa (Formicidae: Ponerinae). Rio Claro, 1998. 125p. Dissertação (Mestrado) - Instituto de Biociências, Universidade Estadual Paulista "Júlio de Mesquita Filho". 